\title{
Liquid Water Cloud Measurements Using the Raman Lidar Technique: Current Understanding and Future Research Needs
}

\author{
Tetsu Sakai, ${ }^{*}$ David N. Whiteman, ${ }^{+}$Felicita Russo, ${ }^{\#}$ David D. Turner, ${ }^{@}$ Igor VeselovskiI, ${ }^{\&}$ \\ S. HARVEY MElfi, ${ }^{+}$TOMOHIRO NAGAI, ${ }^{*}$ AND YuZO MANO* \\ * Meteorological Research Institute, Tsukuba, Ibaraki, Japan \\ ${ }^{+}$NASA Goddard Space Flight Center, Greenbelt, Maryland \\ \# Italian National Agency for New Technologies, Energy and Sustainable Economic Development, Bologna, Italy \\ ${ }^{@}$ NOAA/National Severe Storms Laboratory, Norman, Oklahoma \\ \& Physics Instrumentation Center, General Physics Institute, Moscow, Russia
}

(Manuscript received 8 May 2012, in final form 10 January 2013)

\begin{abstract}
This paper describes recent work in the Raman lidar liquid water cloud measurement technique. The range-resolved spectral measurements at the National Aeronautics and Space Administration Goddard Space Flight Center indicate that the Raman backscattering spectra measured in and below low clouds agree well with theoretical spectra for vapor and liquid water. The calibration coefficients of the liquid water measurement for the Raman lidar at the Atmospheric Radiation Measurement Program Southern Great Plains site of the U.S. Department of Energy were determined by comparison with the liquid water path (LWP) obtained with Atmospheric Emitted Radiance Interferometer (AERI) and the liquid water content (LWC) obtained with the millimeter wavelength cloud radar and water vapor radiometer (MMCRWVR) together. These comparisons were used to estimate the Raman liquid water cross-sectional value. The results indicate a bias consistent with an effective liquid water Raman cross-sectional value that is $28 \%-46 \%$ lower than published, which may be explained by the fact that the difference in the detectors' sensitivity has not been accounted for. The LWP of a thin altostratus cloud showed good qualitative agreement between lidar retrievals and AERI. However, the overall ensemble of comparisons of LWP showed considerable scatter, possibly because of the different fields of view of the instruments, the 350-m distance between the instruments, and the horizontal inhomogeneity of the clouds. The LWC profiles for a thick stratus cloud showed agreement between lidar retrievals and MMCR-WVR between the cloud base and $150 \mathrm{~m}$ above that where the optical depth was less than 3 . Areas requiring further research in this technique are discussed.
\end{abstract}

\section{Introduction}

Liquid water clouds play an important role in the earth's energy balance by scattering and absorbing solar and terrestrial radiation (e.g., Turner et al. 2007b). The influence of the clouds on the radiation balance depends on their microphysical properties such as liquid water content, number concentration and droplet size distribution. These properties are affected by the microphysical properties of the aerosols from which they form, and the thermodynamic and dynamic environmental conditions (e.g., humidity structure, vertical velocity). For the study

Corresponding author address: Tetsu Sakai, Meteorological Research Institute, 1-1 Nagamine, Tsukuba, Ibaraki 305-0052, Japan. E-mail: tetsu@mri-jma.go.jp of the effect of aerosols on clouds, it is important to measure the aerosol and cloud properties in the lower portion of the cloud; this being the region of droplet formation and rapid growth (e.g., Mordy 1959; Lamb and Verlinde 2011). Also, it is desirable to measure these properties in the same atmospheric volume using a single instrument because different instruments have different spatial and temporal resolutions and volumes, resulting in uncertainties in studying aerosol-cloud processes. The Raman lidar offers the potential to measure, simultaneously and in the same atmospheric volume, aerosols, water vapor, and liquid cloud properties in this critical droplet formation region. For that reason, we investigated further this measurement technique. This paper focuses on the liquid water measurement technique since it has not been well studied and verified.

DOI: 10.1175/JTECH-D-12-00099.1 
The first report of the range-resolved observation of the Raman scattering by liquid water cloud (fog) was Bukin et al. (1983). Since that time, Melfi et al. (1997) have discussed the use of Raman scattering from cloud droplets to quantify the liquid water content of clouds. They measured excess (apparently supersaturating) signal in the Raman water vapor channel from the cloud and attributed it to the Raman scattering by liquid droplets. Whiteman and Melfi (1999) extended this work and presented a technique for computing the liquid water content, mean radius, and number concentration of droplets by using the Raman and Mie backscattering signals from clouds. However, the measurements were with broadband filters, where the liquid and vapor signals were together in a single channel. Veselovskii et al. (2000) measured the Raman water vapor and liquid water backscattering separately, but not simultaneously, by using interference filters. They observed increases in the liquid water signals both in the clouds and in the boundary layer compared to that above the top of the boundary layer. They attributed the liquid water signal in the boundary layer to water-coated aerosols. Rizi et al. (2004) measured water vapor and liquid water signals simultaneously in separate channels and concluded that estimating the liquid water content is possible when sampling low-level clouds if the spectral efficiencies of the lidar channel can be measured and/or estimated, the water vapor calibration constant is evaluated, and the ratio between the differential Raman backscattering cross sections of water vapor and liquid/ droplet is known. Whiteman et al. (2010) demonstrated airborne retrievals of cloud liquid water content, droplet radius, and number concentration where the droplet size distribution obtained from those measurements were in good agreement with the literature.

One major problem in the previous studies is that there were few comparisons of the lidar-derived cloud properties with those obtained with other measurements in order to attempt to validate the technique. Because the magnitude of the Raman backscattering cross section of water droplets is not well known (Veselovskii et al. 2002) and the wavelength of fluorescence of airborne particles likely overlaps the Raman wavelength (Manninen et al. 2009), we first wanted to confirm with spectral measurements that the lidar does detect the Raman liquid water backscattering from clouds and that those measurements are in reasonable agreement with expectation. We then calibrated the lidar signal in an appropriate manner.

Thus, in this study we first measured the backscattering spectrum from a water cloud over the National Aeronautics and Space Administration (NASA) Goddard Space Flight Center (GSFC) in Greenbelt, Maryland. We

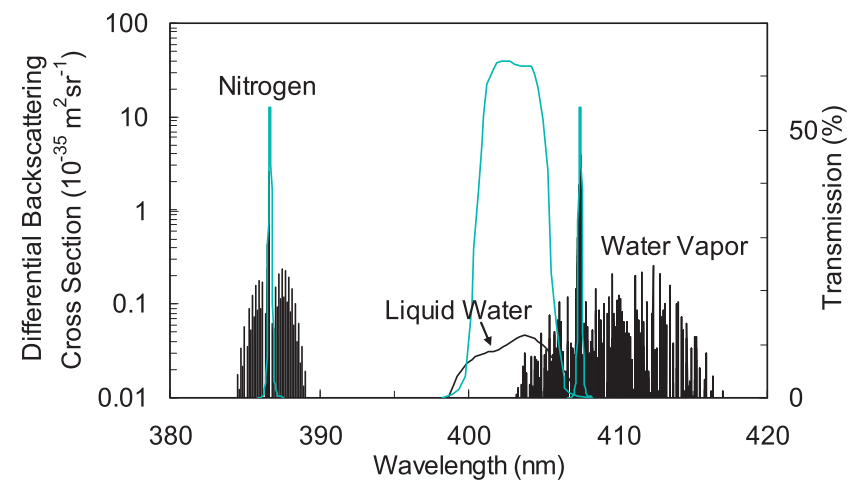

FIG. 1. Differential backscattering cross sections of Raman LW, $\mathrm{WV}$, and $\mathrm{N}_{2}$ excited by $354.7-\mathrm{nm}$ radiation at $300 \mathrm{~K}$. Curve for LW uses an arbitrary scaling. Transmission curves (blue) of the IFs for the Raman lidar at the ARM site are referenced to the right axis.

then analyzed data obtained with the Raman lidar at the Southern Great Plains (SGP) site of the U.S. Department of Energy's Atmospheric Radiation Measurement Program (ARM), where calibration coefficients for the lidar were obtained by comparisons with 1) the Atmospheric Emitted Radiance Interferometer (AERI) and 2) the millimeter wavelength cloud radar and water vapor radiometer (MMCR-WVR) measurements. The content of this paper is as follows. Section 2 describes the methods for measuring liquid water with the Raman lidar. Section 3 shows the results of the spectral measurements acquired at NASA GSFC and time series of measurements from the ARM SGP site. Section 4 discusses the current uncertainties of this technique by focusing on aerosol fluorescence and the Raman cross section. Section 5 summarizes this study.

\section{Raman liquid water measurement technique and instrumentation}

\section{a. Principle of Raman liquid water measurement technique}

The measurement of liquid water content by lidar is based on Raman backscattering by cloud droplets. The laser emits pulses of light (we use the tripled Nd:YAG wavelength of $354.7 \mathrm{~nm}$ ) and light backscattered by cloud droplets is collected with the receiving telescope. The lidar return contains the different backscatter photons that are separated into Raman $(403.2 \mathrm{~nm}$ for liquid water, $407.5 \mathrm{~nm}$ for water vapor, and $386.7 \mathrm{~nm}$ for nitrogen) and Rayleigh-Mie $(354.7 \mathrm{~nm})$ components using dichroic beam splitters and interference filters (IFs). Figure 1 shows the differential Raman backscattering cross sections of these atmospheric components 
TABLE 1. Specification of lidar spectrometer at NASA GSFC.

\begin{tabular}{lc}
\hline \hline & Transmitter \\
Laser & Tripled Nd:YAG \\
Wavelength & $354.7 \mathrm{~nm}$ \\
Pulse energy & $260 \mathrm{~mJ}$ \\
Pulse repetition frequency & $50 \mathrm{~Hz}$ \\
Beam diameter & $3 \mathrm{~cm}(0.125 \mathrm{mrad}$ divergence) \\
Bandwidth & $\sim 1 \mathrm{~cm}^{-1}$ \\
& Receiver \\
Primary telescope & \\
$\quad$ diameter and f-number & $41 \mathrm{~cm}, \mathrm{f} / 10$ \\
Focal length & $0.75 \mathrm{~m}$ \\
FOV & $0.5 \mathrm{mrad}$ \\
Rejection at $354.7 \mathrm{~nm}$ & $>10^{6}$ \\
Spectrometer & $\mathrm{Czerny-Turner}$ \\
F/\# & $\mathrm{f} / 9.7$ \\
Slit width & $10 \mu \mathrm{m}$ to $2.5 \mathrm{~mm}$ (adjustable) \\
Grating groove density & 300,1200, and 2400 line mm \\
Spectral range & $180-850 \mathrm{~nm}$ \\
Resolution & $0.261,0.078$, and $0.037 \mathrm{~nm}$ \\
Detector & ICCD camera \\
Pixels & $1024 \times 256$ \\
\hline
\end{tabular}

and the transmission curves of the interference filters in use in the lidar at the ARM SGP site.

\section{b. Lidar spectrometer at NASA GSFC}

To confirm that the lidar detects the Raman liquid water backscattering and to study the possible interference of fluorescence in the Raman liquid water measurement, we have implemented a lidar spectrometer at NASA GSFC for measuring the Raman spectrum backscattered by the atmosphere. Table 1 and Fig. 2 show the specifications and a schematic of the lidar spectrometer. It emits laser pulses of light at $354.7 \mathrm{~nm}$ with $260 \mathrm{~mJ}$ pulse ${ }^{-1}$ with a repetition rate of $50 \mathrm{~Hz}$. The light backscattered by the atmosphere is collected with a 41-cm-diameter telescope (LX200EMC, Meade, United States). The light collected with the telescope is separated into the spectral component longer than $\sim 380 \mathrm{~nm}$ (transmission) and shorter than that (reflection). The transmitted light passes a blocking (shortcut) filter to suppress the strong backscattered light entering the fiber-optic bundle, which can induce fluorescence. The total rejection factor of the Rayleigh-Mie signal exceeded $10^{6}$. The light is collimated using a lens and enters the fiber-optic bundle (Ceram Optec 19XUV200/ $220 \mathrm{P} / 2.0 \mathrm{M})$ that possess a numerical aperture of 0.22 . The bundle converts the shape of the light beam from circular to rectangular. The rectangular light beam enters the slit of a spectrometer after passing the lens to match the aperture ratio (f/value) of 9.7 of the spectrometer. The spectrometer is a Czerny-Turner spectrograph (Shamrock SR-750-A, Andor Technology,
United States) equipped with a fast gated intensified charge-coupled device (ICCD) camera (iStar DH720, Andor Technology). The highest spectral resolution of the spectrometer is $0.261 \mathrm{~nm}$ when using a grating with a groove density of 300 lines $\mathrm{mm}^{-1}$, as was the case for the measurements here. The actual resolution used for the measurements made here was $\sim 1.6 \mathrm{~nm}$, realized by widening the entrance slit to increase the signal-to-noise $(\mathrm{S} / \mathrm{N})$ ratio of the measurement. The system measures the spectrum of the backscattered light at one height interval at a time through gating of the ICCD camera. We used a gate width of either 5 or $10 \mu$ s, corresponding to height intervals of 750 or $1500 \mathrm{~m}$, respectively. We accumulated the data for $5 \mathrm{~min}$ to increase the $\mathrm{S} / \mathrm{N}$ ratio. In addition to measuring the spectrum, we measured simultaneously the parallel and perpendicular components of the backscatter signal at $354.7 \mathrm{~nm}$ with respect to the polarization plane of the laser with photomultiplier tubes (PMTs) (R1924, Hamamatsu, Japan) and transient recorder (Licel TR-20, Germany) to obtain the vertical distribution of the cloud. The depolarization ratio can be utilized to distinguish spherical particles from irregularly shaped ones. In this experiment, we used only the parallel channel because we did not optimize the alignment of the polarization of the receiving optics. The location of the lidar is Greenbelt, Maryland $\left(38.99^{\circ} \mathrm{N}, 76.84^{\circ} \mathrm{W}\right.$ and $50 \mathrm{~m}$ above mean sea level).

\section{c. Lidar system at ARM SGP site}

The description of the Raman lidar system at the U.S. Department of Energy ARM site in the Southern Great Plains has been given elsewhere (Goldsmith et al. 1998; Turner and Goldsmith 1999, 2005; Newsom 2009), so we only briefly describe it here. Table 2 shows the specifications of this lidar system. It emits laser pulses of light at $354.7 \mathrm{~nm}$ and detects the backscattered light with a $61-\mathrm{cm}-$ diameter telescope and 10 photomultiplier detectors. The liquid water channel was added to the system in October 2005. For the detection of Raman liquid water backscattering, a broadband IF with the center wavelength $\left(\lambda_{\mathrm{CW}}\right)$ at $403 \mathrm{~nm}$ and full width at half maximum (FWHM) of $6.5 \mathrm{~nm}$ is used (Fig. 1). For the detection of Raman scattering from water vapor and nitrogen, narrowband IFs with $\lambda_{\mathrm{CW}}=407.5$ and $386.7 \mathrm{~nm}$ and FWHM $=0.3 \mathrm{~nm}$ are used (Goldsmith et al. 1998; Turner and Goldsmith 1999). The ARM Raman lidar was upgraded in 2004 to use Licel detection electronics, where the vertical resolution of the data is $7.5 \mathrm{~m}$ vertically and $10 \mathrm{~s}$ temporally (Turner and Goldsmith 2005; Newsom et al. 2009). The acquired raw data are available from the ARM Data Archive (http://www.archive.arm.gov). The location of the lidar is near Lamont, Oklahoma $\left(36.61^{\circ} \mathrm{N}, 97.49^{\circ} \mathrm{W}\right.$ and $311 \mathrm{~m}$ above mean sea level). 


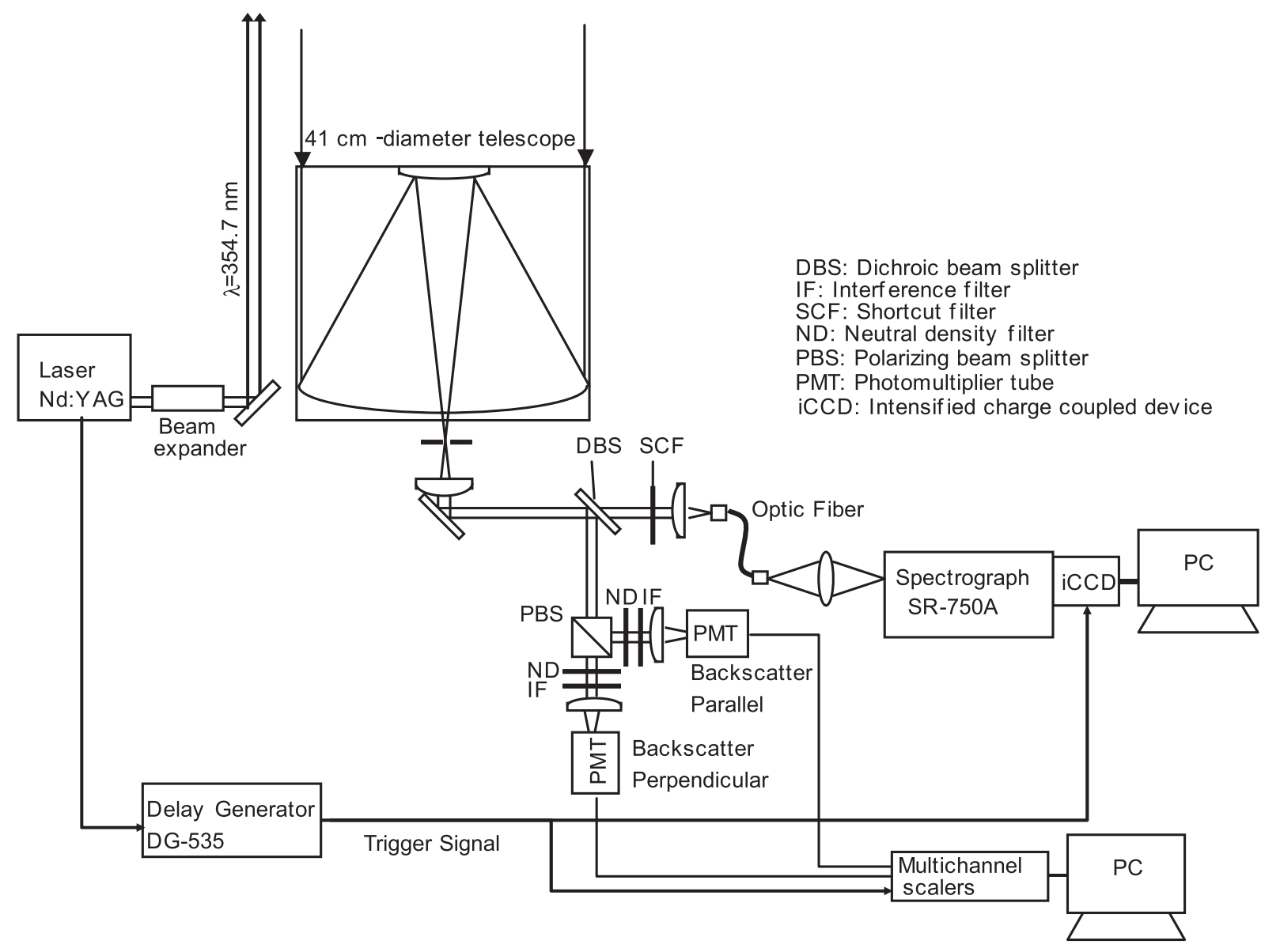

FIG. 2. Schematic of the lidar spectrometer at NASA GSFC.

\section{d. Method for computing liquid water mixing ratio from lidar data}

The standard approach to using the Raman lidar technique to derive liquid water content has been described previously (Whiteman and Melfi 1999; Rizi et al. 2004). Assuming a constant enhancement due to the spherical configuration of the droplet (Veselovskii et al. 2002), the ratio of the liquid water Raman signal and a molecular reference can be used to provide the liquid water mixing ratio in a direct manner (Whiteman and Melfi 1999). There are two potential contributions of signal in the liquid water channel that are not due to liquid water scattering: 1 ) vibrational-rotational (Raman scattered) lines of water vapor and 2) aerosol fluorescence. Here, we introduce correction factors for them. The liquid water mixing ratio (LWR) at height $z$ is then computed from the lidar data using

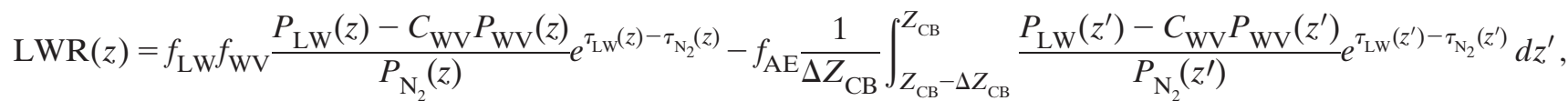

where $P_{x}(z)$ is the background subtracted signal intensity from the height $z$ and the subscripts refer to the Raman liquid water (LW), water vapor (WV), and nitrogen $\left(\mathrm{N}_{2}\right)$ channels; $\tau_{x}$ is the atmospheric (molecular and particle) transmission between the lidar and $z$ at the wavelength $x$. We compute the molecular transmission from the radiosonde-derived atmospheric density and the particle transmission from the nitrogen Raman signal and/or Rayleigh Mie signal using the method described by Sakai et al. (2003). We use the extinction coefficient derived from the Raman $\mathrm{N}_{2}$ signal where the uncertainty in the derived extinction coefficient is lower than $100 \%$ or is estimated from the backscattering coefficient $\left(\beta_{p}\right)$ derived from Mie-Rayleigh and Raman $\mathrm{N}_{2}$ 
TABLE 2. Specification of Raman lidar at ARM SGP site (after Newsom 2009).

\begin{tabular}{|c|c|c|c|}
\hline \multicolumn{4}{|c|}{ Transmitter } \\
\hline Laser & \multicolumn{3}{|c|}{ Tripled Nd:YAG } \\
\hline Wavelength & \multicolumn{3}{|c|}{$354.7 \mathrm{~nm}$} \\
\hline Pulse energy & \multicolumn{3}{|c|}{$300-400 \mathrm{~mJ}$} \\
\hline Pulse repetition frequency & \multicolumn{3}{|c|}{$30 \mathrm{~Hz}$} \\
\hline Beam diameter & \multicolumn{3}{|c|}{$13 \mathrm{~cm}(\sim 0.1 \mathrm{mrad}$ divergence $)$} \\
\hline Bandwidth & \multicolumn{3}{|c|}{$\sim 2 \mathrm{~cm}^{-1}$} \\
\hline \multicolumn{4}{|c|}{ Receiver } \\
\hline Primary telescope diameter and f-number & \multicolumn{3}{|c|}{$61 \mathrm{~cm}, \mathrm{f} / 9.3$} \\
\hline Filter transmission & & \multicolumn{2}{|l|}{$30 \%-40 \%$} \\
\hline \multicolumn{4}{|l|}{ FOV } \\
\hline Wide (WFOV) & \multicolumn{3}{|c|}{$2 \mathrm{mrad}$} \\
\hline Narrow (NFOV) & \multicolumn{3}{|c|}{$0.3 \mathrm{mrad}$} \\
\hline Detection electronics & \multicolumn{3}{|c|}{$\begin{array}{l}\text { Simultaneous photon counting and analog } 7.5-\mathrm{m} \\
\text { range resolution }\end{array}$} \\
\hline & \multicolumn{3}{|c|}{ Wavelength } \\
\hline Detection channels & \multicolumn{2}{|c|}{ Center wavelength (CWL, nm) } & FWHM (nm) \\
\hline Unpolarized elastic (WFOV) (nm) & \multicolumn{2}{|c|}{354.7} & 0.3 \\
\hline Beam parallel elastic (NFOV) (nm) & \multicolumn{2}{|c|}{354.7} & 0.3 \\
\hline Beam perpendicular elastic (NFOV) (nm) & \multicolumn{2}{|c|}{354.7} & 0.3 \\
\hline Water vapor (WFOV and NFOV) (nm) & \multicolumn{2}{|c|}{407.5} & 0.3 \\
\hline $\mathrm{N}_{2}(\mathrm{WFOV}$ and NFOV) $(\mathrm{nm})$ & \multicolumn{2}{|c|}{386.7} & 0.3 \\
\hline Temperature (NFOV) (nm) & \multicolumn{2}{|c|}{353.3} & 0.25 \\
\hline Temperature (NFOV) (nm) & \multicolumn{2}{|c|}{354.3} & 0.25 \\
\hline LW (NFOV) (nm) & \multicolumn{2}{|c|}{403.2} & 6.5 \\
\hline
\end{tabular}

signals by multiplying the extinction-to-backscatter ratio (we assumed $50 \mathrm{sr}$ when the backscattering ratio is lower than 3 for aerosols and 20 sr when the backscattering ratio is equal to or larger than 3 for clouds). The coefficients $f_{x}$ are 1) the calibration coefficient of the liquid water mixing ratio $\left.\left(f_{\mathrm{LW}}\right), 2\right)$ the calibration coefficient of water vapor mixing ratio $\left.\left(f_{\mathrm{WV}}\right), 3\right)$ the fractional contribution of the Raman water vapor signal $\left(C_{\mathrm{WV}}\right)$ in the $\mathrm{LW}$ channel, and 4) the fractional contribution of aerosol florescence ( $\left.f_{\mathrm{AE}}\right)$ to LWR; $z_{\mathrm{CB}}$ is the cloud-base height and $\Delta z_{\mathrm{CB}}=$ $300 \mathrm{~m}$. The $f_{\mathrm{WV}}$ is obtained by a least squares fitting of the lidar data between 0.3 and $4.0 \mathrm{~km}$ in altitude to that obtained with the coincident radiosonde launched approximately $80 \mathrm{~m}$ from the lidar. The uncertainty in $f_{\mathrm{WV}}$ is estimated to be less than 5\% from the standard error of the least squares fitting of the lidar to the radiosonde data.

The $f_{\text {LW }}$ includes the ratio of the effective Raman cross section of water vapor to liquid water and the detection efficiency of the receiving optics that is expressed by (Whiteman 2003)

$$
f_{\mathrm{LW}}=\frac{\int \frac{d \sigma_{\mathrm{WV}}}{d \Omega} \xi_{\mathrm{WV}} d \lambda}{\int \frac{d \sigma_{\mathrm{LW}}}{d \Omega} \xi_{\mathrm{LW}} d \lambda \times G},
$$

where $d \sigma_{x} / d \Omega$ is the differential backscattering Raman cross section at an exciting wavelength of $354.7 \mathrm{~nm}, \xi_{X}$ is the detection efficiency, and $G$ is the gain enhancement factor of the Raman liquid water cross section due to resonances of the spherical droplet (Veselovskii et al. 2002). We assume that the beam overlap factors are equal for the two channels above $0.3 \mathrm{~km}$ in altitude based on the agreement of the lidar-derived water vapor mixing ratio with radiosonde without overlap correction. For the purpose of this study and based on the range of temperatures $(\sim 30 \mathrm{~K})$ encountered, the temperature dependence of the effective Raman cross section is negligible because the variation is less than $0.3 \%$ and $2 \%$ for the liquid water and water vapor, respectively. The aerosol fluorescence is estimated from the average of the uncalibrated LWR below the cloud base between $z_{\mathrm{CB}}$ and $z_{\mathrm{CB}}-\Delta z_{\mathrm{CB}}$, a region where no significant liquid water signal is expected in the absence of precipitation. Fluorescence is a spontaneous emission of a photon by an atom or molecule after a transition into an excited state due to absorption of the incident radiation. The decay time of the aerosol fluorescence is on the order of $10 \mathrm{~ns}$ (Pan et al. 2007), which is shorter than the resolving time of the lidar ( $50 \mathrm{~ns})$. It should be noted that $f_{\mathrm{LW}}, f_{\mathrm{WV}}$, and $C_{\mathrm{Wv}}$ are system constants, whereas $f_{\mathrm{AE}}$ can vary depending on the aerosol properties (size, shape, and chemical composition) in the cloud. We determined these coefficients for the lidar at ARM SGP by comparing with AERI and MMCR-WVR measurements as described in sections $3 \mathrm{~b}$ and $3 \mathrm{c}$. The theoretical values of $f_{\mathrm{LW}}$ and $C_{\mathrm{WV}}$ are calculated to be 0.081 and 
0.035 , respectively, from the Raman cross section of $5.1 \times 10^{-33} \mathrm{~m}^{2} \mathrm{sr}^{-1}$ for liquid water (Ahmad and Iles 2001) and $6.9 \times 10^{-34} \mathrm{~m}^{2} \mathrm{sr}^{-1}$ for water vapor (Avila et al. 2004). The spectral shapes of the Raman band are given by Walrafen (1967) and Whiteman et al. (1999) for liquid water and Avila et al. (2004) for water vapor. The transmission ratio of the receiving optics of LW to WV is 1.2 from the manufacturer's data on the beam splitters and interference filters used for separating and sampling these signals (Russo 2007). We assumed that $G=2$ (Veselovskii et al. 2002). There are several possible uncertainties in the coefficients as follows:

1) The manufacturer's sensitivity curves show that there is little difference between the quantum efficiency of PMTs at the liquid water and water vapor wavelengths, so these quantum efficiency values have been assumed to be the same. However, the sensitivity of individual PMTs can differ significantly and this possibility has not been accounted for.

2) The Raman cross section of liquid water measured in laboratory experiments varies by $30 \%$ at an exciting wavelength of $354.7 \mathrm{~nm}$ (Ahmad and Iles 2001; Li and Meyers 1990; Faris and Copeland 1997).

3) Although likely of a much smaller magnitude than the two other effects mentioned, there still may be a question of whether the embedded dipole model simulations accurately account for all the spherical resonance of droplets (Veselovskii et al. 2002).

The combination of these three could contribute a significant error to these theoretical calculations. It is for that reason that we will show later the calculation of these values using an optimization scheme. The liquid water content $(\mathrm{LWC})$ is calculated as $\mathrm{LWC}=\mathrm{LWR} \times \rho$, where $\rho$ is the atmospheric density that was obtained from the radiosonde measurements.

\section{Results}

\section{a. Backscatter spectrum measurement over NASA GSFC}

To study the spectrum of Raman liquid water signal from clouds, we measured spectrally resolved backscattering from a low cloud over NASA GSFC from 2013 to 2029 LT 15 November 2011. During the measurement period, a thin cloud was present at an altitude range between 1.8 and $2.0 \mathrm{~km}$ (top-right panels in Figs. 3 and 4). Therefore, Figs. 3 and 4 show the spectra measured in and below the cloud where the ICCD range gate was set to capture two different spectra: one between the altitude ranges from 1.6 to $2.4 \mathrm{~km}$ (Fig. 3), where the cloud was located; and the other between the ground

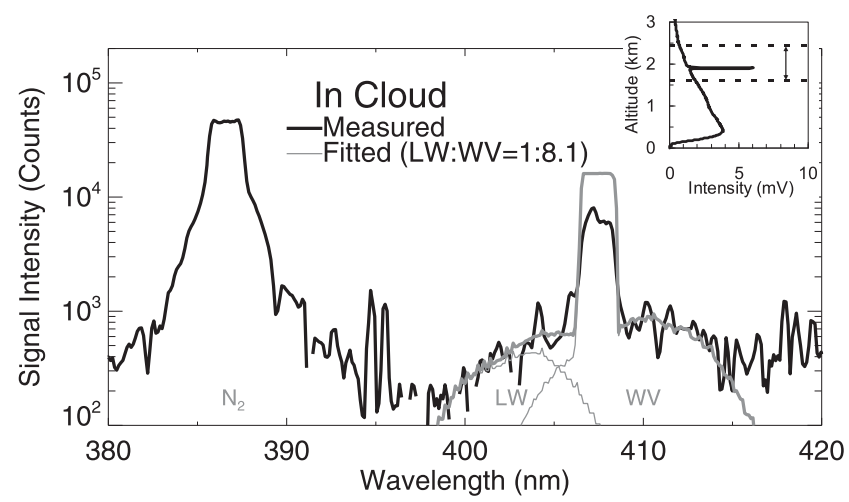

FIG. 3. Backscattering spectrum in cloud between 1.6 and $2.4 \mathrm{~km}$ in altitude over GSFC at 2024-2029 LT 15 Nov 2011. Thin gray curves show the theoretical Raman intensity fitted to the measured spectrum with molecular number concentration ratio of LW to $\mathrm{WV}$ as 1 to 8.1. Top right inset shows the vertical distribution of backscattering intensity at $354.7 \mathrm{~nm}$ at 2026-2029 LT and horizontal dotted lines with arrow show the height range of spectrum measurement.

and $1.6 \mathrm{~km}$ (Fig. 4), which was used as a clear-air spectrum. The temperature in the height range of the cloud was between 278 and $280 \mathrm{~K}$ at $2000 \mathrm{LT}$ based on the nearest radiosonde observation site (Dulles International Airport, which is a distance of $52 \mathrm{~km}$ away), indicating that the phase of cloud particles was likely liquid. Changes in the cloud structure during the measurement period were only a small concern because lidar measurements showed these variations to be small.

The spectrum measured in the cloud (Fig. 3) shows that, although the signal-to-noise ratio of the data was low, the spectral intensity increased for the wavelength ranges from 400 to $420 \mathrm{~nm}$ and from 380 to $390 \mathrm{~nm}$. The spectral shape in the 400-410-nm range fits well to the convolution of theoretical Raman cross sections of liquid water and water vapor with the molecular number concentration ratio of liquid water to water vapor $(r)$ of

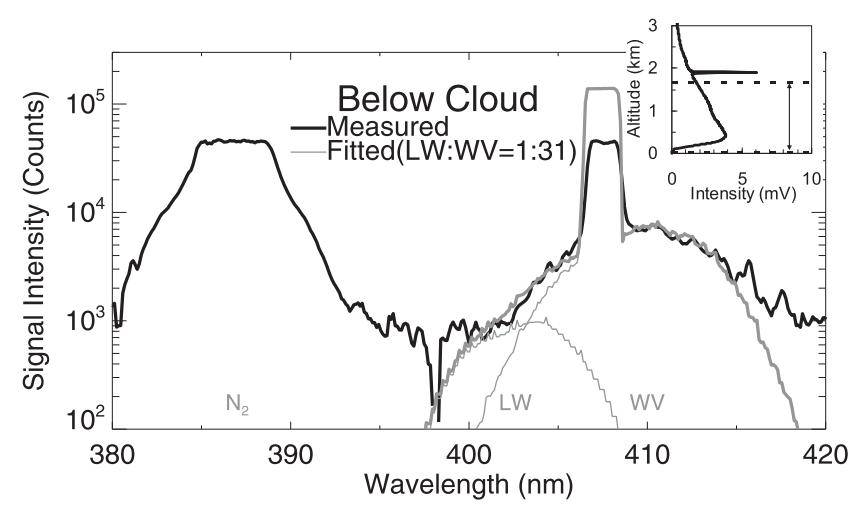

FIG. 4. As in Fig. 3, but below the cloud between 0 and $1.6 \mathrm{~km}$ in altitude over GSFC at 2013-2018 LT 15 Nov 2011 and with the thin gray curves fitted with a ratio of LW to WV as 1 to 31 . 
1/8.1. We determined this ratio by fitting the theoretical curve to the measured spectrum to minimize the function defined by

$\chi^{2}=\sum_{i=1}^{N} \frac{\left[I_{\mathrm{obs}}\left(\lambda_{\mathrm{i}}\right)-r I_{\mathrm{LW}}\left(\lambda_{\mathrm{i}}\right)-(1-r) I_{\mathrm{WV}}\left(\lambda_{\mathrm{i}}\right)\right]^{2}}{\delta I_{\mathrm{obs}}\left(\lambda_{\mathrm{i}}\right)^{2}}$,

where $I_{\mathrm{obs}}, I_{\mathrm{LW}}$, and $I_{\mathrm{WV}}$ are the observed and theoretical Raman liquid water and water vapor intensities at $\lambda_{i}$ respectively. The uncertainty in the observed intensities $\delta I_{\text {obs }}$ was estimated by $\sqrt{I_{\mathrm{obs}}}$ assuming the Poisson statistics. We set $\lambda_{1}=398 \mathrm{~nm}$ and $\lambda_{N}=415 \mathrm{~nm}$, with $N=$ 147 , and exclude the data points between 406 and $408 \mathrm{~nm}$ because the observed signals might be saturated as discussed below.

The water vapor peak measured at $408 \mathrm{~nm}$ is 2.5 times lower than the theoretical value; this may be due to detector saturation. We estimate that the average LWC in the cloud $\left(1.8-2.0 \mathrm{~km}\right.$ in altitude) was $0.34 \pm 0.08 \mathrm{~g} \mathrm{~m}^{-3}$ from the number concentration ratio of water vapor to liquid water in the spectrum (Fig. 3), Raman cross sections of water vapor (Avila et al. 2004) and liquid water (Ahmad and Iles 2001), and the radiosonde-derived vertically integrated water vapor content for the altitude range of the spectrum (1.6-2.4 km in altitude), which is consistent with the value of low stratus cloud (Pruppacher and Klett 1997). The uncertainty in the LWC was estimated using standard error propagation from the uncertainties of $14 \%$ for the number concentration ratio of water vapor to liquid water; $10 \%$ for the Raman cross section of water vapor based on Penny and Lapp (1976); and $17 \%$ for the liquid water based on the standard deviation of cross section reported by Ahmad and Iles (2001), Li and Myers (1990) and Faris and Copeland (1997); and $2 \%$ in the radiosonde-derived water vapor content (Miloschevich et al. 2006). The large increase in the $380-390-\mathrm{nm}$ range is the Raman backscattering by nitrogen $\left(\lambda_{\mathrm{CW}}=386.7 \mathrm{~nm}\right)$.

The spectrum below the cloud (Fig. 4) shows that the intensity increased in the spectral ranges from 400 to 420 and from 380 to $390 \mathrm{~nm}$. The spectral shape fits well the combination of Raman liquid water and water vapor spectra with $r=1 / 31$ except for the peak at $408 \mathrm{~nm}$, where the observed value was 3.2 times lower than theoretical value, possibly due to the detector saturation. It should be noted that the intensity at the 400-406$\mathrm{nm}$ range (Raman liquid water region) is much lower than that in cloud (Fig. 3). The small increase in signal between 400 and $406 \mathrm{~nm}$ in Fig. 4 may be due to waterclad aerosols, as suggested by Veselovskii et al. (2000) and Rizi et al. (2004). From these results we confirmed that the lidar could detect the Raman liquid water backscattering from the clouds and distinguish the cloud from the cloud-free air in this case. However, it is desirable to improve the signal-to-noise ratio of the spectrum to increase the confidence of the detection of the Raman liquid water signal. Kim et al. (2009) have also measured the Raman spectrum of the atmosphere at a wavelength range from 402 to $411 \mathrm{~nm}$ by using a multichannel PMT. They found a difference in the shape of the spectrum between a cloudy day and a clear day, although there was ambiguity in the result because the spectral resolution of their measurement was too coarse to resolve the spectral shapes of the Raman bands.

There is a possible enhancement at wavelengths longer than $415 \mathrm{~nm}$ that could be due to fluorescence by aerosols in the air (we discuss this possibility later in section 4a). The width of the Raman nitrogen spectrum measured below the cloud (Fig. 4) is larger than that in cloud (Fig. 3). A possible explanation for that is the cross talk of the charge-coupled device (CCD) elements due to the strong signal from the lower altitude.

\section{b. Thin inhomogeneous clouds (altostratus) measurements over ARM SGP}

To obtain the lidar calibration coefficients $\left(f_{x}\right.$ and $\left.C_{\mathrm{WV}}\right)$ shown in Eq. (1), we compared the liquid water path (LWP) obtained with the lidar and AERI over the SGP ARM site. The AERI measures the absolute infrared sky spectral radiance between 3 and $19.2 \mu \mathrm{m}$ directly above the instrument with a resolution of $0.5 \mathrm{~cm}^{-1}$ (Knuteson et al. 2004a,b). From the measured radiance, LWP and liquid cloud optical thickness were obtained using the mixed-phase cloud retrieval algorithm (MIXCRA) developed by Turner (2005). The temporal resolution of the AERI data was 19-25s. The uncertainty (random error) in the AERI-derived LWP is less than $4 \%$ for LWP $<50 \mathrm{~g} \mathrm{~m}^{-2}$ (Turner 2007). Importantly, the field of view (FOV) of the AERI is $\sim 46 \mathrm{mrad}$ in FWHM, which is larger than that of the Raman lidar $(0.3 \mathrm{mrad})$. The difference in FOV can cause errors in determining the calibration coefficients because of the sampling differences between the two instruments. For comparison, we also show LWP obtained with WVR. The WVR measures downwelling radiant energy at 23.8 and 31.4 GHz. The FOVs of the WVR are $5.9^{\circ}$ and $4.5^{\circ}(100$ and $79 \mathrm{mrad}$, respectively). From these observations, LWP and precipitable water vapor (PWV) are obtained using the microwave radiometer retrieval (MWRRET) algorithm developed by Turner et al. (2007a). The retrieval approach uses an optimal estimation methodology where the covariance of the observations is propagated through the retrieval to provide estimates of the uncertainty in the retrieved parameters. The temporal resolution of the WVR data was $20 \mathrm{~s}$. The 


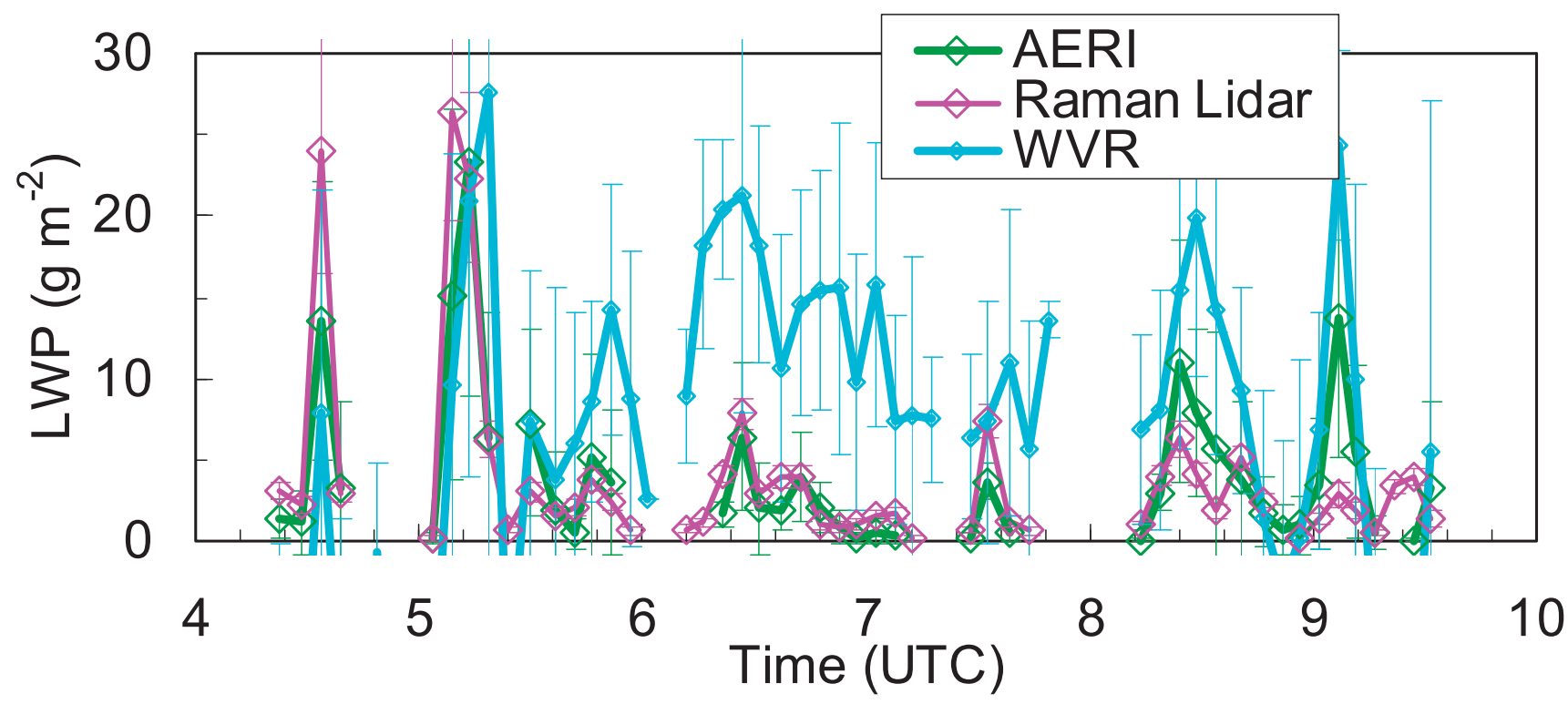

FIG. 5. Temporal variation of LWP obtained with the Raman lidar (magenta), AERI (green), and WVR (blue) for the period 0400-1000 UTC 9 Aug 2006 over SGP ARM site. Error bars show the standard deviation of data points averaged for 5 min for AERI and WVR, and the measurement uncertainty estimated from the uncertainty in the lidar signals using the Poisson statistics for the Raman lidar.

uncertainty in the derived LWP is at least $20 \mathrm{~g} \mathrm{~m}^{-2}$ (Turner et al. 2007a).

To compare the AERI and Raman lidar measurements, we needed to select clouds that had sufficiently low optical depth such that the lidar could profile through the entire cloud, since the AERI and WVR provide only LWP. Figure 5 shows the temporal variation of the LWP obtained for the period 0400-1000 UTC 9 August 2006. The temporal resolution used was $5 \mathrm{~min}$ to improve the signal-to-noise ratio of the lidar retrievals. To compute LWP from the lidar data, we integrated LWC values vertically from below the cloud base to above the cloud top (3.0-4.5 km in altitude, see Fig. 7). The uncertainty in the LWP (LWC) is estimated from the uncertainty in the lidar signals assuming the Poisson statistics (Whiteman 2003).

The qualitative agreement between the lidar and AERI is quite good, whereas the WVR showed values higher than these instruments for values lower than $10 \mathrm{~g} \mathrm{~m}^{-2}$. We recall that the uncertainty of the WVR is approximately $20 \mathrm{~g} \mathrm{~m}^{-2}$, which offers a possible explanation for the disagreement of the WVR results with the other instruments. We obtained calibration coefficients for the lidar $\left[f_{\mathrm{LW}}, C_{\mathrm{WV}}\right.$, and $f_{\mathrm{AE}}$ in Eq. (1)] by fitting the lidar data to the AERI-derived LWP by varying the values of $f_{\mathrm{LW}}$ from 0.10 to 0.20 in intervals of $0.01, C_{\mathrm{WV}}$ from 0.01 to 0.03 in intervals of 0.01 , and $f_{\mathrm{AE}}$ from 0 to 2 in intervals of 0.1 . We determined the values by performing a simple linear regression for each set of $f_{x}$ and $C_{\mathrm{WV}}$ values and finding the values that result in a slope that is closest to one, and an intercept that is closest to zero. Table 3 shows the results that provided the best fit to the data. The optimum values were determined to be $f_{\mathrm{LW}}=0.17, C_{\mathrm{WV}}=0.01$, and $f_{\mathrm{AE}}=1.0$ for this case. The uncertainty in the $f_{x}$ values are estimated to be at least $11 \%$ considering the statistical uncertainties of the lidar signals $(<10 \%)$, and the measurement uncertainty in the AERI-derived LWP $(<4 \%)$. However, the uncertainty should be larger than that because of the sampling uncertainty associated with the differing FOVs, the $\sim 350 \mathrm{~m}$ separation between the Raman lidar and AERI, and inhomogeneities in the cloud field. The fractional contribution of the Raman water vapor signal to the LW channel (i.e., the ratio of $C_{\mathrm{Wv}} P_{\mathrm{WV}}$ to $P_{\mathrm{LW}}$ ) was $15 \%$ and the fractional contribution of the aerosol fluorescence to the LWR [i.e., the ratio of the second term to the first

TABLE 3. Result of determining calibration coefficients of Raman lidar in this study. Asterisk denotes regression equations: LWP(Raman lidar $)=$ slope $\times$ LWP $($ AERI $)+$ intercept or LWC $($ Raman lidar $)=$ slope $\times$ LWC $($ MMCR-WVR $)+$ intercept.

\begin{tabular}{|c|c|c|c|c|c|c|c|c|}
\hline \multirow[b]{2}{*}{ Instrument } & \multirow[b]{2}{*}{ Date } & \multicolumn{3}{|c|}{ Parameter } & \multicolumn{4}{|c|}{ Regression* } \\
\hline & & $f_{\mathrm{LW}}$ & $C_{\mathrm{WV}}$ & $f$ & Slope & Intercept & Correlation coefficient & Number of data points \\
\hline AERI & 9 Aug 2006 & 0.17 & 0.01 & 1.0 & 0.97 & $0.31 \mathrm{~g} \mathrm{~m}^{-2}$ & 0.80 & 41 \\
\hline MMCR-WVR & 9 Apr 2008 & 0.12 & 0.03 & 1.8 & 1.00 & $-9.7 \times 10^{-3} \mathrm{~g} \mathrm{~m}^{-3}$ & 0.93 & 12 \\
\hline MMCR-WVR & 3 May 2008 & 0.18 & 0.02 & 0.4 & 1.00 & $-6.1 \times 10^{-3} \mathrm{~g} \mathrm{~m}^{-3}$ & 0.96 & 7 \\
\hline
\end{tabular}




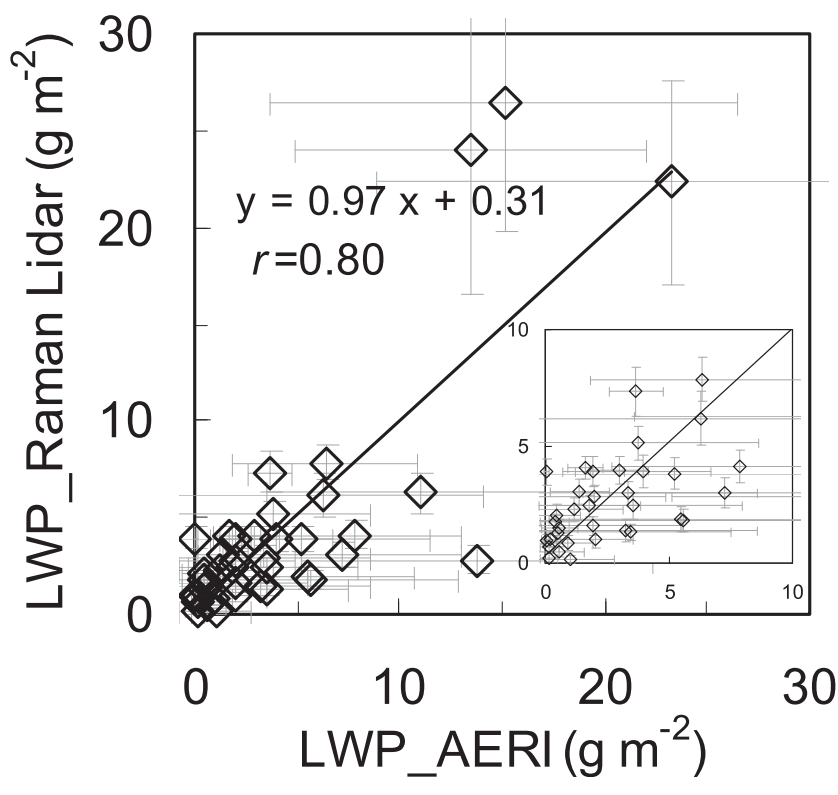

FIG. 6. Scatterplot of LWP obtained with AERI and Raman lidar for the period shown in Fig. 7. The equation in the figure is result of linear regression with $y=\mathrm{LWP}($ Raman lidar) and $x=\mathrm{LWP}$ (AERI); $r$ is correlation coefficient. Close-up for the small LWP values is the inset.

term of the right side of Eq. (1)] is $41 \%$, suggesting that the aerosol fluorescence was not negligible and that the derived LWR is sensitive to $f_{\mathrm{AE}}$ for this case.

A comparison of these values with the theoretical ones indicates that $f_{\mathrm{LW}}$ is 2.1-2.2 times larger than the theory $\left(f_{\mathrm{LW}}=0.081\right)$. We believe that the major reasons for the difference are the assumption that the detection efficiency of PMTs for LW and $\mathrm{N}_{2}$ channels are equal and the uncertainty in the Raman cross section of liquid water as discussed in section $2 \mathrm{~d}$. We believe that uncertainty in $G$ is smaller than the others because it is based on the electromagnetic theory and computation. The value of $C_{\mathrm{WV}}$ is 3.5 times smaller than that expected by theory $\left(C_{\mathrm{wV}}=0.035\right)$. The possible reason for the smaller contribution of the Raman water vapor signal to the liquid water channel than expected for this case is that the cross talk of the liquid water channel differs from that computed from the characteristics of the optical components (e.g., spectral transmission of the dichroic beam splitter for the WV channel placed before the $\mathrm{LW}$ channel). The value $f_{\mathrm{AE}}=0.9-1.0$ suggests that aerosol fluorescence intensity does not enhance in the cloud droplets and is almost the same inside the cloud as it is below cloud for this case. Using these coefficients, the lidar-derived LWP varied between 0 and $27 \mathrm{~g} \mathrm{~m}^{-2}$ (Fig. 5). The correlation coefficient is 0.80 for 41 data points between 0400 and 0932 UTC (Fig. 6). The difference in LWP between the lidar and AERI is large at 0824 and 0906 UTC, possibly because of the inhomogeneity of the cloud. Figure 7 shows the temporal and vertical cross section of backscattering ratio at $354.7 \mathrm{~nm}$ for the same time period as Fig. 5. The temporal resolution is $10 \mathrm{~s}$ and the vertical resolution is $60 \mathrm{~m}$. We can see in the figure that the clouds with backscatter ratio higher than 10 were present between the altitude range of $3-4 \mathrm{~km}$ and the vertical distribution varied significantly with time. This variability likely was an influence on the differences in LWP between the lidar and the AERI. The lidar-derived LWP would be higher than that derived with AERI if the lidar pointed at the high LWP region of the inhomogeneous clouds, whereas it would be lower if the lidar pointed at the low LWP region.

Figure 8 shows the temporal variation of the cloud optical thickness. The value for the lidar data was computed from the attenuation of the Raman nitrogen signal from an altitude of $3.0-4.5 \mathrm{~km}$ - that is, the same altitude range as for the LWP retrieval. The lidar-derived value ranged from 0 to 2.43 . It should be mentioned that the temporal variation of the optical thickness is similar to LWP, indicating the proportionality of the cloud optical

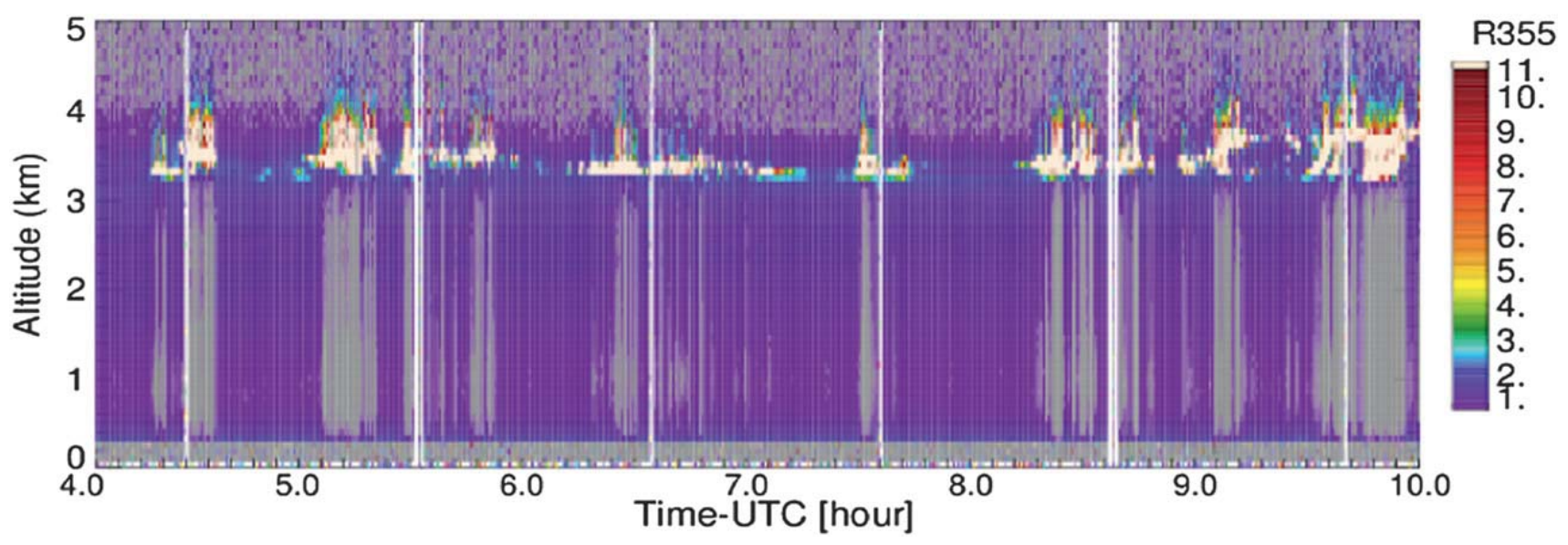

FIG. 7. Temporal and vertical cross section of backscattering ratio at $354.7 \mathrm{~nm}$ for the same time period as in Fig. 6. 


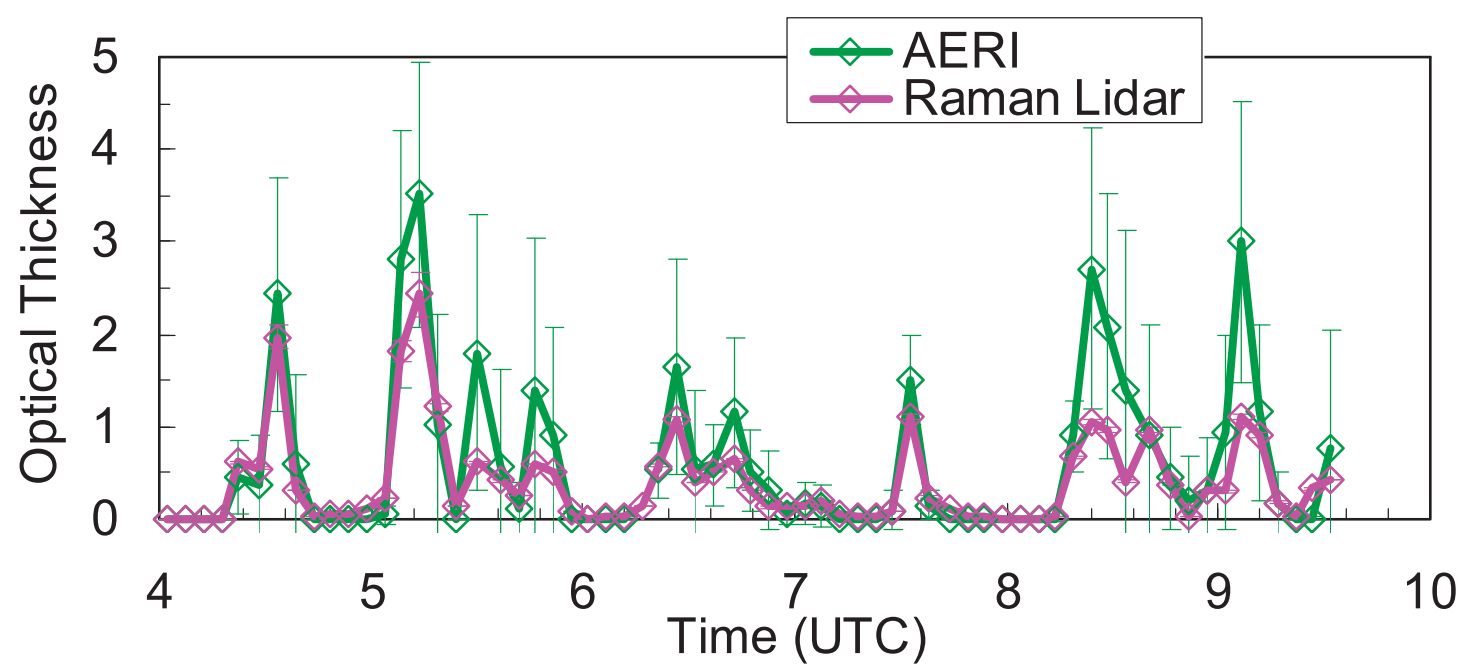

FIG. 8. As in Fig. 7, but for the optical thickness obtained with the Raman lidar (magenta) and AERI (green). Error bars show the standard deviation of the data points averaged for $5 \mathrm{~min}$ for AERI and the measurement uncertainty estimated from the lidar signals for the Raman lidar.

thickness to LWP (Fig. 9). The regression analysis between the lidar-derived optical thickness and LWP shows that the slope is $9.57 \mathrm{~g} \mathrm{~m}^{-2}$ and the intercept is $-1.35 \mathrm{~g} \mathrm{~m}^{-2}$ with the correlation coefficient of 0.88 . If we omit the three large LWP values $\left(>20 \mathrm{~g} \mathrm{~m}^{-2}\right)$ in the regression analysis, then the slope and the intercept of the regression are 5.0 and $0.16 \mathrm{~g} \mathrm{~m}^{-2}$, respectively, and the correlation coefficient is the same $(0.88)$ as that obtained including the three large LWP values. We mention that the peak values of the optical thickness derived with the lidar were consistently lower than the AERI ones. The reason for this is not likely to be the multiple scattering effects on the Raman nitrogen signal that can result in underestimation of the optical thickness because we obtained almost the same values from $\beta_{p}$ assuming the lidar ratio of $20 \mathrm{sr}$.

Figure 10 shows a scatterplot of LWP obtained with the Raman lidar and AERI on 1 May; 5 June; 13 and 26 July; and 9, 10, and 31 August 2006-on all of these days the overhead cloud was determined to be warm and could be fully profiled by the Raman lidar. The method for computing LWP is the same as before. We selected the data for the cloud optical thickness smaller than 3 to ensure that the lidar fully profiled the cloud. The number of data points used was 147 . The correlation coefficient between the data was 0.66 . One probable reason for the low correlation is that the two instruments measured different cloud volumes because of 1) the difference in the location $(\sim 350 \mathrm{~m})$ between the instruments, 2$)$ the difference in the FOV $(0.2 \mathrm{mrad}$ and the beam divergence of $<0.1 \mathrm{mrad}$ for the lidar and $46 \mathrm{mrad}$ for AERI, corresponding to the horizontal diameter of $<43 \mathrm{~cm}$ for the lidar and $138 \mathrm{~m}$ for AERI at an altitude of $3 \mathrm{~km}$ ), and 3 ) the inhomogeneity of the cloud distribution. We estimated the inhomogeneity of the cloud distribution from the high-temporal-resolution AERI retrievals (19-25-s resolution) and found that the standard deviation of the LWP were 10.6 and $4.1 \mathrm{~g} \mathrm{~m}^{-2}$ for the period of Figs. 10 and 6, respectively. This suggests a larger cloud inhomogeneity in the data shown in Fig. 10 than those in Fig. 6 and helps to explain the better agreement shown in Fig. 6. Thus, for the validation of

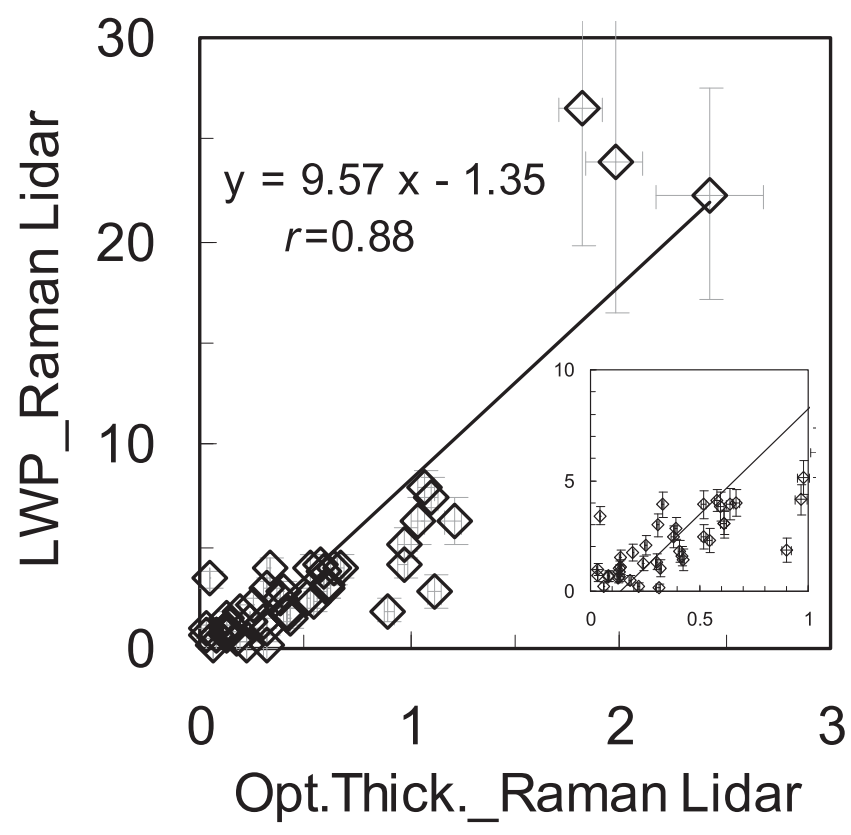

FIG. 9. Scatterplot of LWP as a function of optical thickness obtained with the Raman lidar for the same time period as in Figs. 5 and 8 . The equation in the figure is the result of linear regression with $y=$ LWP, $x=$ optical thickness, and $r$ is correlation coefficient. Close-up for the small optical thickness values is the inset. 


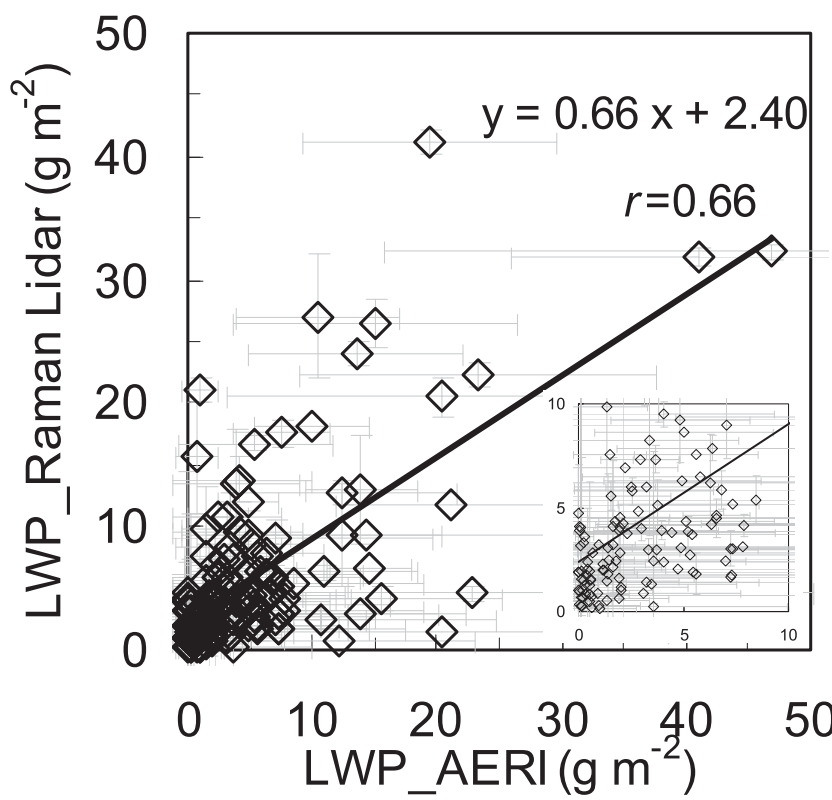

FIG. 10. Scatterplot of LWP for the values with the Raman lidar and AERI for cloud optical thickness lower than 3 for 1 May31 Aug 2006 over ARM SGP site. Error bars show the standard deviation for AERI-derived LWP and measurement uncertainty estimated from the uncertainty in the lidar signal for the lidarderived LWP. The equation in the figure is the result of linear regression with $y=\mathrm{LWP}(\operatorname{Raman}$ lidar $), x=\mathrm{LWP}(\mathrm{AERI})$, and $r$ is the correlation coefficient.

the lidar measurements, it is better to compare measurements under homogeneous cloud conditions to minimize the sampling differences between the instruments. We will show examples of such comparisons in the next subsection.

\section{c. Thick homogeneous clouds (low stratus) measurements over ARM SGP}

To minimize the influence of the sampling differences between the instruments, we analyzed homogeneous stratus clouds over the ARM SGP site in 2008. In this case, we compared the lidar-derived LWC with those obtained by MMCR-WVR, as we could not obtain LWP from the lidar data because the cloud was so thick that it strongly attenuated the laser beam and prevented full penetration of the cloud. The MMCR measures the vertical distributions of the reflectivity, vertical velocity, and Doppler spectrum width at $34.86 \mathrm{GHz}$ (wavelength $8.66 \mathrm{~mm}$ ) (Moran et al. 1998). The beamwidth is $0.2^{\circ}(3.5 \mathrm{mrad})$. The vertical distribution of LWC is derived from the MMCR-derived reflectivity and WVR-derived LWP using the method described by Dong et al. (1998) and Dong and Mace (2003). The MMCR-WVR-derived data were obtained from Cloud Retrieval Ensemble Dataset (CRED; Zhao et al. 2012) in the ARM Data Archive (http://www.arm.gov/data/eval/49).
The resolution of the data was $1 \mathrm{~h}$ in time and $45 \mathrm{~m}$ in the vertical. The uncertainty in the MMCR-WVR-retrieved LWC is $30 \%$ under the best conditions (Ebell et al. 2010).

Figure 11 shows the vertical distributions of LWC obtained with the lidar and MMCR-WVR for the period from 0300 to 0600 UTC 9 April 2008. The lidar data are averaged every $1 \mathrm{~h}(0300-0400,0400-0500$, and 0500-0600). The derived vertical profiles of LWC from the lidar are consistently subadiabatic from the cloud base to $150 \mathrm{~m}$ above the cloud base $(0.9-1.05 \mathrm{~km}$ in altitude), demonstrating physical feasibility of the results, and agree generally well with the MMCR-WVR retrievals. The calibration coefficients obtained by fitting the lidar data to the MMCR-WVR data in that altitude region were $f_{\mathrm{LW}}=0.12, C_{\mathrm{WV}}=0.03$, and $f_{\mathrm{AE}}=1.8$, which are different from those obtained by comparison with AERI. The reason for the differences is possibly the measurement uncertainties of $30 \%$ in LWC for MMCRWVR data (Ebell et al. 2010) and $~ 10 \%$ for the lidar data estimated from the uncertainty in the lidar signals. The fractional contributions of the Raman water vapor to the LW channel and the aerosol fluorescence to the LWR are $30 \%$ and $<1 \%$, respectively, indicating that LWC is not sensitive to $f_{\mathrm{AE}}$ for this case.

Above $150 \mathrm{~m}$ from the cloud base, the laser could not penetrate effectively into the cloud but the WVR and MMCR radiowave of could penetrate it. The penetration optical depth at which the lidar and MMCR-WVR results tended to diverge was approximately 3 . This was estimated from $\beta_{p}$ assuming the lidar ratio of $20 \mathrm{sr}$. The total liquid cloud optical thicknesses obtained with MMCR were 11, 18, and 13 for those periods.

We mention that the presence of signal-induced noise has been observed above $1.1 \mathrm{~km}$ in altitude and influences the results. Studies of the detectors' response (not shown) indicate that detector nonlinearities may also be influencing the results shown for large optical depths.

Figure 12 shows the temporal and vertical cross section of $\beta_{p}$ and LWC obtained from the lidar. The temporal resolution is $5 \mathrm{~min}$ and the vertical resolution is $45 \mathrm{~m}$. We can see in the figure the cloud base is stably present between 0.9 and $1.0 \mathrm{~km}$ for three hours. The value of LWC increased from 0 to $0.1 \mathrm{~g} \mathrm{~m}^{-3}$ from the cloud base to $150 \mathrm{~m}$ above that.

Figure 13 shows the scatterplot of LWC obtained with the lidar and MMCR-WVR near the cloud base for the 17 data points on 9 and 17 April 2008. Although the number of the data points is small, the correlation coefficient between these data (0.82) is higher than that obtained with the comparison with AERI (0.66), partly because the homogeneity of the cloud distribution. However, it would be preferable to increase the number of 

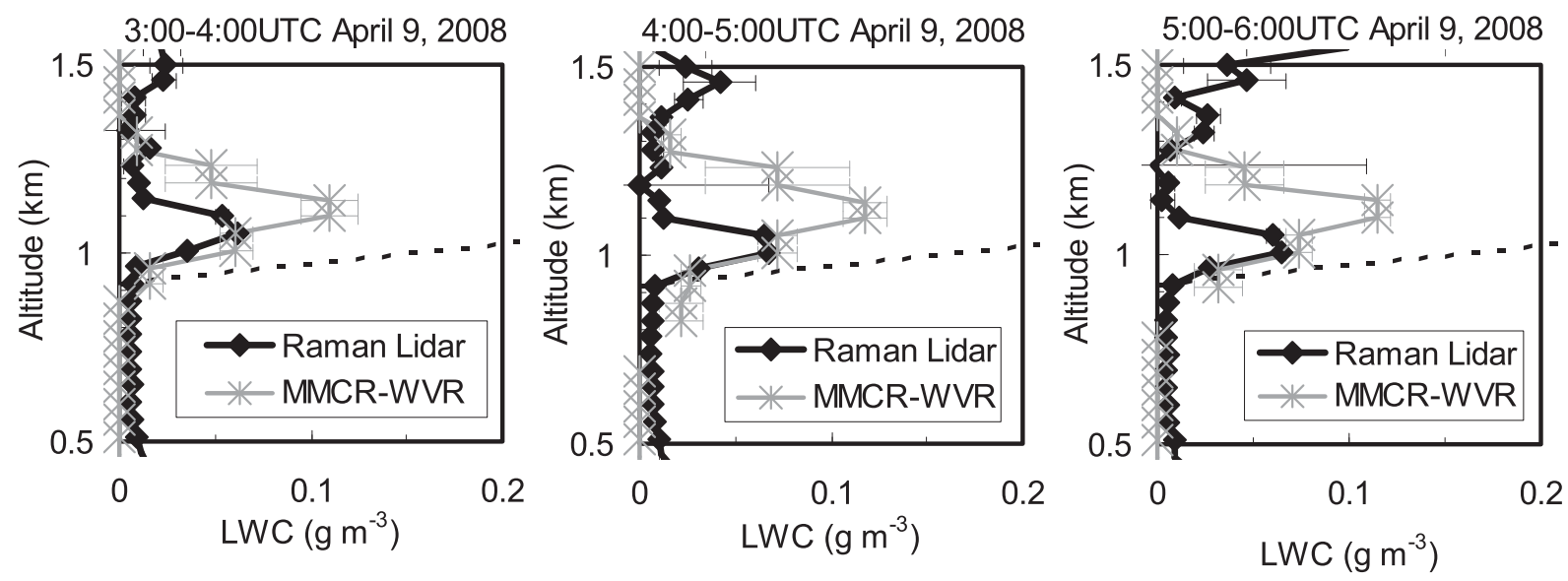

FIG. 11. Vertical distributions of hourly averaged LWC obtained with the Raman lidar (black line with solid diamond) and MMCRWVR (gray line with asterisk) for (from left to right) the period 0300-0600 UTC 9 Apr 2008 over ARM SGP site. Black dotted lines show the adiabatic profile. Error bars show the standard deviation for the MMCR-WVR and the measurement uncertainty estimated from the uncertainty in the lidar signals for the Raman lidar.

comparisons in the future to increase the statistical confidence of the correlation.

\section{Discussion}

\section{a. Aerosol fluorescence}

The results shown in the previous section (section 3c) were likely under the conditions of small influence of aerosol fluorescence on the liquid water signals because we did not observe any significant increase in the liquid water signal in cloud-free air. However, we have found some data that showed a large influence possibly due to aerosol fluorescence. Figure 14 shows the vertical distributions of LWC obtained with the Raman lidar and MMCR-WVR (left panel) and $\beta_{p}$ and depolarization ratio obtained with the lidar (right panel) for 0800-0900 UTC 10 August 2006 over the ARM SGP site. It showed a peak in LWC with $0.025 \mathrm{~g} \mathrm{~m}^{-3}$ at an altitude of $3.9 \mathrm{~km}$ where $\beta_{p}$ showed a large peak with
$0.055 \mathrm{~km}^{-1} \mathrm{sr}^{-1}$. The MMCR-WVR LWC data also showed a peak at the altitude. This peak was probably cloud because the relative humidity computed from the lidar-derived water vapor mixing ratio and radiosondederived temperature and pressure was saturated with respect to water. The figure also shows a large peak in LWC with $0.4 \mathrm{~g} \mathrm{~m}^{-3}$ at an altitude of $2 \mathrm{~km}$ where $\beta_{p}$ was $0.0018 \mathrm{~km}^{-1} \mathrm{sr}^{-1}$. This peak was probably not Raman backscattering from a water cloud because the relative humidity was unsaturated (55\%). We suspect that this was the fluorescence by aerosols at the LW wavelength $(403 \mathrm{~nm})$. However, we have no information about the aerosol composition in that region for the period. The depolarization ratios are lower than $10 \%$ in that region, suggesting that spherical or near-spherical particles were predominant. The backward trajectory computed by Hybrid Single Particle Lagrangian Integrated Trajectory (HYSPLIT; Draxler and Rolph 2012) have shown that the air parcel of the aerosol layer had been carried over the southern part of United States for 3 days before,

\section{(a) Particle Backscattering Coeffient}

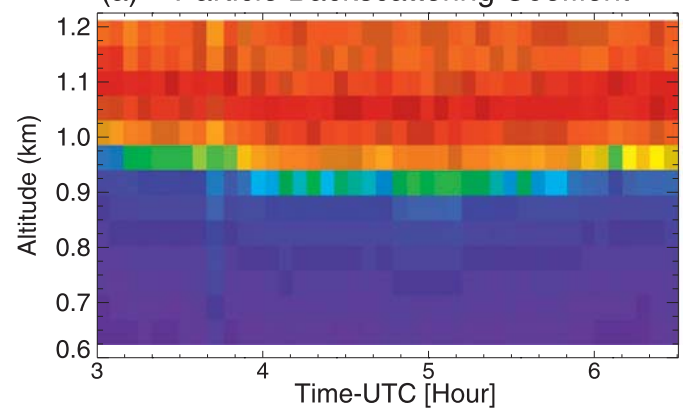

(b) Liquid Water Content

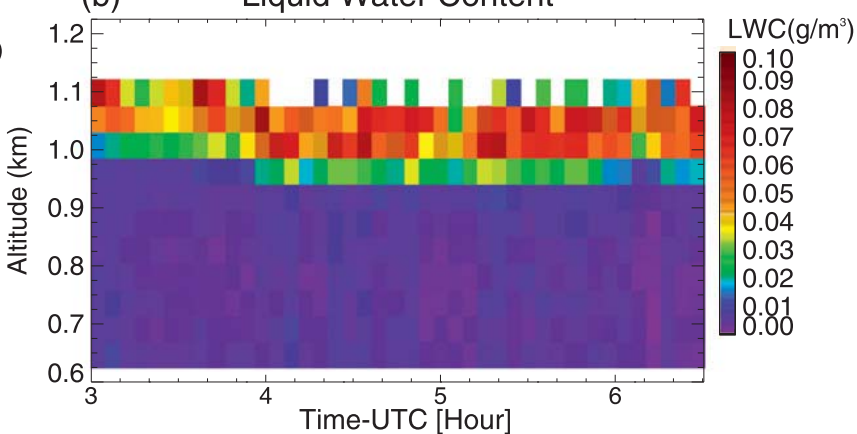

FIG. 12. Temporal and vertical cross sections of (a) $\beta_{p}$ and (b) LWC obtained with the Raman lidar for the period 0300-0630 UTC 9 Apr 2008 over ARM SGP site. 


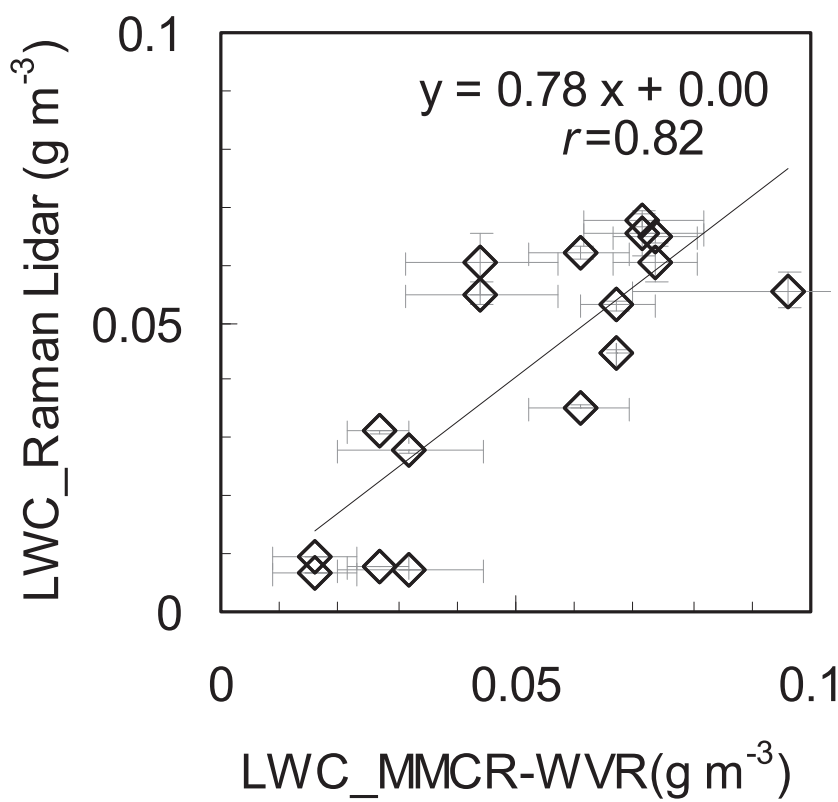

FIG. 13. Scatterplot of LWC obtained with the Raman lidar and MMCR-WVR on 9 and 17 Apr 2008 over ARM SGP site. Error bars show the standard deviation for the MMCR-WVR and measurement uncertainty estimated from the uncertainty in the lidar signals for the Raman lidar. The equation in the figure is the result of linear regression with $y=\mathrm{LWC}($ Raman lidar), $x=\mathrm{LWC}$ (MMCR-WVR), and $r$ is the correlation coefficient.

when the presence of smoke in Mississippi and Alabama was predicted by the global aerosol model (Navy Aerosol Analysis and Prediction System model, description and results available from the web pages of the Naval Research Laboratory, Monterey, California; http://www.nrlmry.navy.mil/aerosol). This suggests that smoke particles were the source of the fluorescence in the aerosol layer. However, we cannot make this conclusion with certainty because many atmospheric aerosols exhibit fluorescence: chemically aged terpenes, fungal spores, polycyclic aromatic hydrocarbons, bacteria, cellulose pollens, and mixtures of various organic carbon compounds (Pinnick et al. 2013; Lighthart and Mohr 1994; Jaenicke et al. 2007). We found that the lidar data in August 2006 showed a similar increase in LWC in the lower and midtroposphere in the absence of clouds. To confirm that aerosol fluorescence can interfere with the Raman LW signal, we measured the fluorescence spectrum of pine pollen in the laboratory at GSFC. To measure the fluorescence spectrum, we used a spectrofluorometer (Fluorolog, HORIBA Jobin Yvon). The incident light wavelength was $354.7 \mathrm{~nm}$ with $1-\mathrm{nm}$ width and the detection angle is $167.5^{\circ}$ to the incident light. Figure 15 shows the spectrum of the pollen fluorescence, which has a broad increase at wavelengths larger than $365 \mathrm{~nm}$ that overlaps the Raman liquid water scattering band and the transmission curve of the LW channel.

Although the absolute fluorescence cross section was unavailable in these laboratory experiments, we can expect that the aerosol fluorescence may interfere with the LW signal under the conditions of high fluorescence aerosol concentration in the atmosphere. For example, Gelbwachs and Birnbaum (1973) reported the aerosol fluorescence intensity at the wavelength range of 610 $660 \mathrm{~nm}$ excited at $488 \mathrm{~nm}$ in the ambient atmosphere on a smoggy day in California was 7 times as large as that
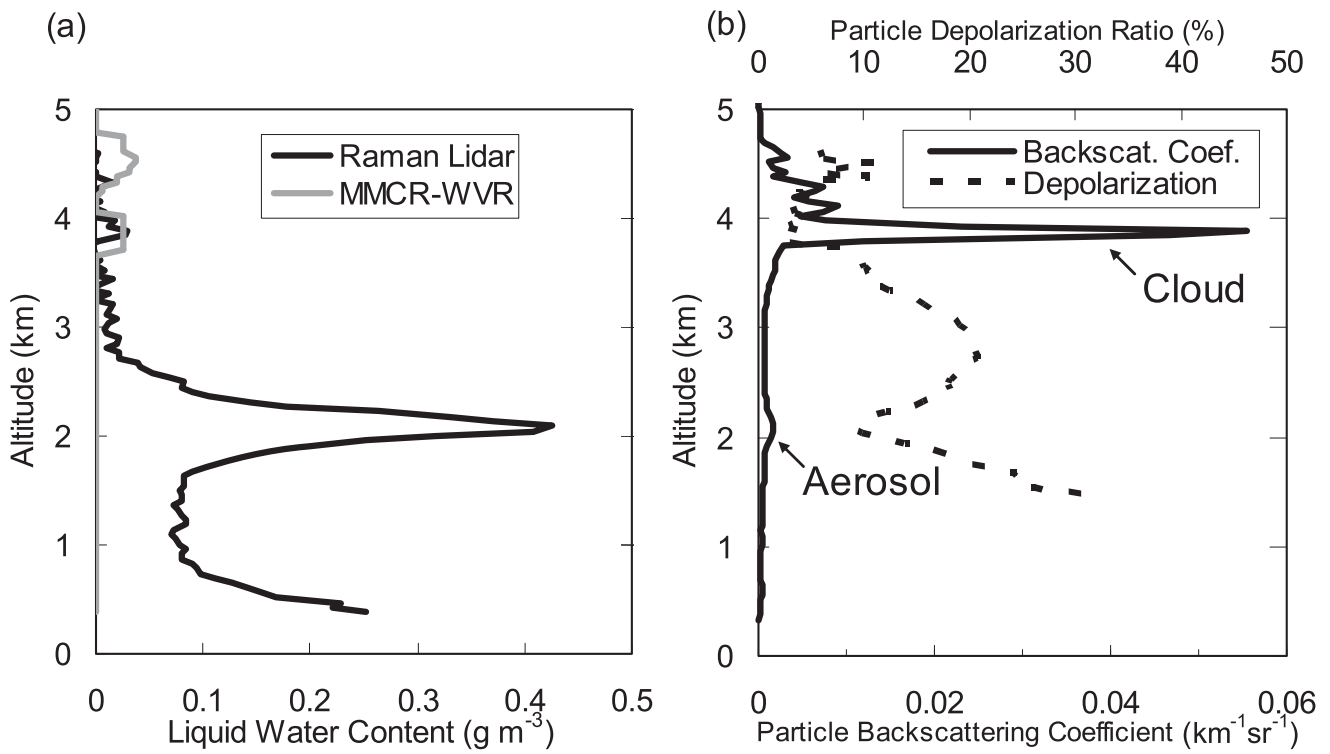

FIG. 14. (a) Vertical distribution of LWC obtained with the Raman lidar (black) and MMCR-WVR (gray) for 0800-0900 UTC 10 Aug 2006 over ARM SGP site. (b) Vertical distributions of particle backscattering coefficient (solid) and depolarization ratio (dotted) obtained with Raman lidar for the same time period. 


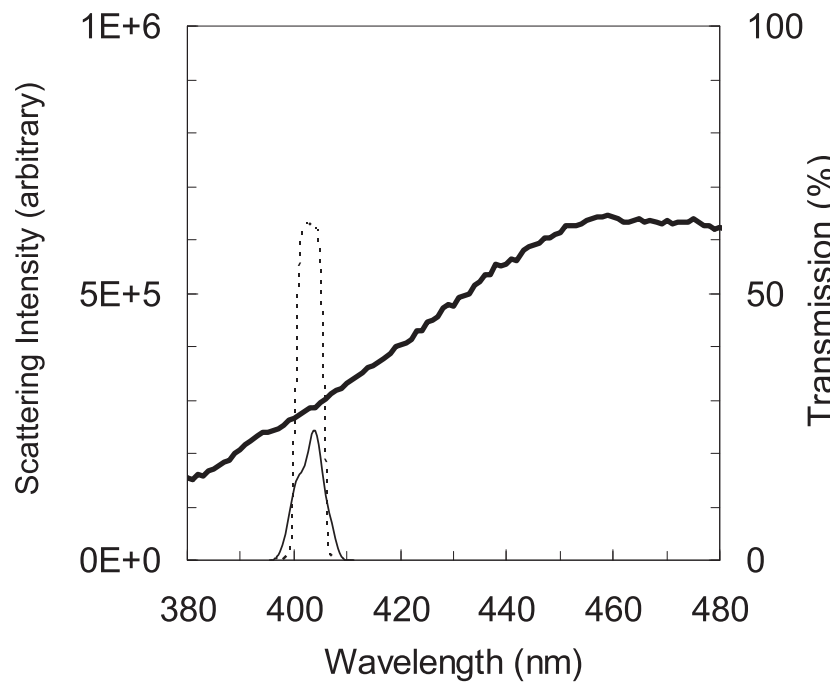

FIG. 15. Fluorescence spectrum of pine pollen (thick solid line.) Thin solid line shows the Raman spectrum of liquid water. Thin dotted line shows transmission of IF for the LW channel of the ARM lidar.

due to $\mathrm{NO}_{2}$ at $0.25 \mathrm{ppm}$. This intensity $\left(2.4 \times 10^{-11} \mathrm{~m}^{-1}\right.$ $\mathrm{sr}^{-1}$ ) would correspond to $0.2 \mathrm{~g} \mathrm{~m}^{-3}$ in LWC using the parameters given by Gelbwachs (1973) of the $\mathrm{NO}_{2}$ absorption coefficient of $10^{-3} \mathrm{~m}^{-1} \mathrm{ppm}^{-1}$ at $488 \mathrm{~nm}$, the factor by which the $\mathrm{NO}_{2}$ fluorescence quenched at $1 \mathrm{~atm}$ of $2 \times 10^{-5}$ and detection wavelength width of $6.5 \mathrm{~nm}$ for the ARM lidar (Table 2). This result indicates that fluorescence is very likely to be a contributor to the liquid water signal under the conditions observed by Gelbwachs and Birnbaum (1973). Immler et al. (2005) have also observed inelastic scattering from an aerosol layer in the lowermost stratosphere with the Raman lidar at a wavelength at $407 \mathrm{~nm}$ with a bandwidth of $5.6 \mathrm{~nm}$. They attributed it to the fluorescence by smoke particles from a forest fire. Sugimoto et al. (2012) have observed broad fluorescence at wavelengths shorter than $510 \mathrm{~nm}$ excited at $354.7 \mathrm{~nm}$ from Asian dust and airpollution aerosols transported from urban and industrial areas in the lower troposphere. The influence of fluorescence on the WV signal is generally less because of the typical use of narrow bandwidth filters (e.g., $0.3 \mathrm{~nm}$ ) for water vapor detection. However, care must be taken in analyzing Raman water vapor lidar data when measuring very low water vapor concentrations under conditions where aerosols may be present because fluorescence may be artificially enhancing the signal even for lidar systems that use narrow band detection.

\section{b Liquid water Raman backscattering cross section}

We estimate the Raman backscattering cross section of liquid water from $f_{\mathrm{LW}}$ that was determined by the

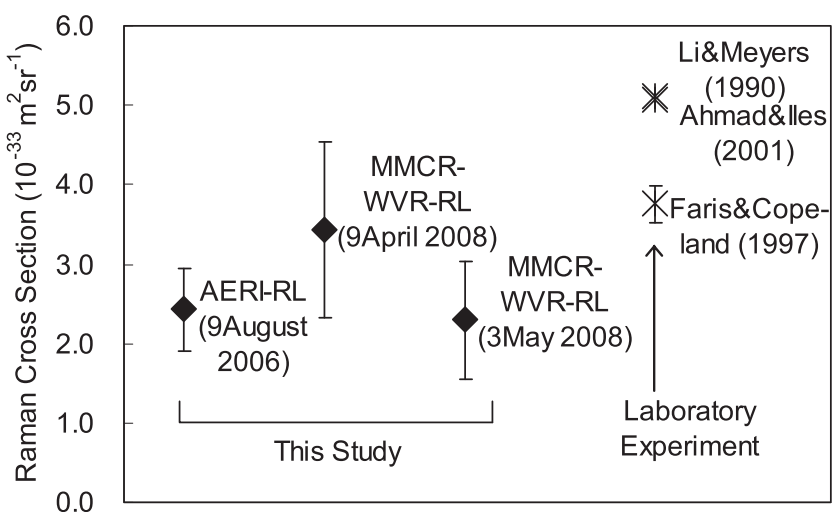

FIG. 16. Raman backscattering cross section of LW at an exciting wavelength of $354.7 \mathrm{~nm}$ estimated from this study (solid diamonds) and those reported by laboratory experiments (asterisk). Error bars of this study indicate the uncertainties estimated from the measurement uncertainties of the two instruments. Error bar of Faris and Copeland (1997) indicates the single standard deviation of the measurement. Values of Li and Meyers (1990) and Ahmad and Iles (2001) are overlapped.

comparisons of the lidar data with AERI and MMCRWVR (sections $3 b$ and $3 c$ ). In addition, we show the result estimated using the data obtained between 1.1 and $1.5 \mathrm{~km}$ for $0800-0859$ UTC 3 May 2008, when the correlation coefficient between the lidar-derived LWC and MMCR-WVR-derived LWC is the highest $(r=$ $0.96)$ with $f_{\mathrm{LW}}=0.18, C_{\mathrm{WV}}=0.02$, and $f_{\mathrm{AE}}=0.4$. To estimate the liquid water Raman cross section from $f_{\mathrm{LW}}$, we used Eq. (2) and the parameters given in section $2 \mathrm{~d}$ $\left(d \sigma_{\mathrm{WV}} / d \Omega, \xi_{\mathrm{WV}}, \xi_{\mathrm{LW}}\right.$, and $\left.G\right)$ except for the liquid water cross section. Figure 16 shows the results as well as those reported from recent laboratory experiments. The uncertainties are calculated from the measurement uncertainties in LWC of each instrument and the uncertainty in the water vapor Raman cross section using standard error propagation. They are 4\% for AERI (Turner 2007), $30 \%$ for MMCR-WVR (Ebell et al. 2010), 18\% in August 2006 and 5\% in April-May 2008 for the Raman lidar estimated from the uncertainty in the lidar signals, $5 \%$ in $C_{\mathrm{WV}}$ (section $2 \mathrm{~d}$ ), and $10 \%$ in the water vapor Raman cross section based on Penny and Lapp (1976). The Raman liquid water cross-sectional values estimated from the comparisons vary from $(2.3 \pm 0.7) \times 10^{-33}$ to $(3.4 \pm 1.1) \times 10^{-33} \mathrm{~m}^{2} \mathrm{sr}^{-1}$ with an ensemble mean of $2.7 \times 10^{-33} \mathrm{~m}^{2} \mathrm{sr}^{-1}$, which is $46 \%$ lower than those of Ahmad and Iles (2001) and Li and Meyers (1990), and $28 \%$ lower than that of Faris and Copeland (1997). The relative standard deviation of the ensemble mean for the lidar data is $23 \%$, which is close to the maximum uncertainty of the cross section reported by Faris and Copeland (1997). A reasonable explanation for the discrepancy is that errors may have been introduced in the detection efficiency ratio of LW and WV channels, 
which we assumed to be one. As mentioned earlier, the sensitivity of individual PMTs can differ significantly. It would be possible to measure the ratio of detection efficiency of these two channels by interchanging the PMTs or IFs (Vaughan et al. 1988). The lamp mapping technique is also a promising solution for determining the overall detection efficiency of the receiving system (Venable et al. 2011). However, many more lidar cases are needed to increase the number of comparisons to increase the statistical confidence of the estimate of Raman cross-section value because the large differences of $f_{\mathrm{LW}}, C_{\mathrm{WV}}$, and $f_{\mathrm{AE}}$ in thin and thick clouds (Table 3 ) could be due to the differences in the cloud characteristics (i.e., LWC, droplet size distribution, and number concentration) and the aerosol fluorescence effect.

\section{Summary and conclusions}

This paper has described the current state of our research into the Raman liquid water cloud measurement technique based on the results of spectroscopic measurements acquired at NASA GSFC and the analysis of data from the ARM SGP site. The conclusions of this study are as follows:

1) The observed backscattering spectra in/below cloud were spectrally similar to laboratory and theoretical calculations of Raman liquid water and water vapor spectra over GSFC on 15 November 2011. The intensity ratio of liquid water to water vapor in the cloud was much higher than that below the cloud and was consistent with reasonable values of cloud liquid water content.

2) The coefficients for computing LWR from the ARM lidar were determined by comparison with AERI and MMCR-WVR to be $f_{\mathrm{LW}}=0.12-0.18, C_{\mathrm{WV}}=$ $0.01-0.03$, and $f_{\mathrm{AE}}=0.4-1.8$ for the data in 2006 and 2008. The possible reason for the large ranges in these coefficients is the measurement errors of the instruments (4\% for AERI, 30\% for MMCR-WVR, and $2 \%-18 \%$ for the Raman lidar) and the sampling differences of the two instruments.

3) Strong qualitative correlation was obtained in the LWP time series of lidar and AERI for some cases, although considerable scatter in the overall ensemble of comparisons may be due to the different fields of view of the instruments, distance between the instruments, and the horizontal inhomogeneity of the clouds.

4) The LWC of a homogeneous low-level stratus cloud was obtained near the cloud base to $150 \mathrm{~m}$ above where the optical depth was less than 3 and was in good agreement with retrievals from MMCR-WVR.
5) We show a significant enhancement of the liquid water signal in the lidar measurement in August in 2006 that we believe to be due to aerosol fluorescence. This is a concern both for liquid water and water vapor measurements by lidar.

6) The Raman backscattering cross section of liquid water obtained from this study is $28 \%-46 \%$ lower than the most current laboratory values for the Raman liquid water cross section, although possible differences in lidar PMT detector efficiencies have not yet been accounted for. The uncertainty of the Raman lidar results nearly overlaps with those of Faris and Copeland (1997).

Suggestions for improving the Raman lidar liquid water cloud measurement technique are as follows:

1) Measure the cloud spectrum with high $\mathrm{S} / \mathrm{N}$ ratio under the conditions of high/low aerosol loading to study the influence of the aerosol fluorescence on the Raman liquid water channel.

2) Increase the number of comparisons of the lidarderived cloud properties with those obtained with the other instruments (e.g., AERI, MMCR-WVR, and aircraft-based instruments) to further test the lidar measurement.

3) Measure the lidar detector's efficiency ratio of LW and WV (or $\mathrm{N}_{2}$ ) channels to reduce the uncertainty in the Raman backscattering cross section of liquid water that is estimated from the comparison.

4) Work on correcting for the nonlinear response of the detectors in the presence of thick clouds and/or to improve the linearity of the detector's response to the strong signal.

With success at reducing the measurement uncertainties of the Raman lidar cloud liquid water retrievals, the Raman lidar can potentially provide a complete set of measurements for studying the aerosol indirect effect without concern for the different fields of view, and temporal and spatial resolutions of the different instruments.

Acknowledgments. This work was supported by the Ministry of Education, Culture, Sports, Science and Technology (MEXT).

\section{REFERENCES}

Ahmad, S. R., and A. Iles, 2001: Pre-resonance Raman excitation profile of the $3400 \mathrm{~cm}^{-1}$ mode of liquid water. J. Raman Spectrosc., 32, 649-655.

Avila, G., J. M. Fernández, G. Tejeda, and S. Montero, 2004: The Raman spectra and cross-sections of $\mathrm{H}_{2} \mathrm{O}, \mathrm{D}_{2} \mathrm{O}$, and HDO in the OH/OD stretching regions. J. Mol. Spectrosc., 228, $38-65$. 
Bukin, O. A., U. Kh. Kopvillem, S. Yu. Stolyarchuk, and V. A. Tyapkin, 1983: Investigation of Raman spectra of atmospheric gases. J. Appl. Spectrosc., 38, 561-564.

Dong, X., and G. G. Mace, 2003: Profiles of low-level stratus cloud microphysics deduced from ground-based measurements. J. Atmos. Oceanic Technol., 20, 42-53.

— T. P. Ackerman, and E. E. Clothiaux, 1998: Parameterizations of the microphysical and shortwave radiative properties of boundary layer stratus from ground-based measurements. J. Geophys. Res., 103 (D24), 31 681-31393.

Draxler, R. R., and G. D. Rolph, cited 2012: HYSPLIT (Hybrid Single-Particle Lagrangian Integrated Trajectory) model access via NOAA ARL READY website. NOAA Air Resources Laboratory, Silver Spring, MD. [Available online at http:// ready.arl.noaa.gov/HYSPLIT.php.]

Ebell, K., U. Löhnert, S. Crewell, and D. D. Turner, 2010: On characterizing the error in a remotely sensed liquid water content profile. Atmos. Res., 98, 57-68.

Faris, G. W., and R. A. Copeland, 1997: Wavelength dependence of the Raman cross section for liquid water. Appl. Opt., 36, 26862688.

Gelbwachs, J., 1973: $\mathrm{NO}_{2}$ lidar comparison: Fluorescence vs backscattered differential absorption. Appl. Opt., 12, 28122813.

_ and M. Birnbaum, 1973: Fluorescence of atmospheric aerosols and lidar implications. Appl. Opt., 12, 2442-2447.

Goldsmith, J. E. M., F. H. Blair, S. E. Bisson, and D. D. Turner, 1998: Turn-key Raman lidar for profiling atmospheric water vapor, clouds, and aerosols. Appl. Opt., 37, 4979-4990.

Immler, F., D. Engelbart, and O. Schrems, 2005: Fluorescence from atmospheric aerosol detected by a lidar indicates biogenic particles in the lowermost stratosphere. Atmos. Chem. Phys., 5, 345-355.

Jaenicke, R., S. Matthias-Maser, and S. Gruber, 2007: Omnipresence of biological material in the atmosphere. Environ. Chem., 4, 217-220.

Kim, D., S. Baik, H. Cha, Y. Kim, and I. Song, 2009: Lidar measurement of a full Raman spectrum of water by using a multichannel detector. J. Korean Phys. Soc., 54, 38-43.

Knuteson, R. O., and Coauthors, 2004a: Atmospheric Emitted Radiance Interferometer. Part I: Instrument design. J. Atmos. Oceanic Technol., 21, 1763-1776.

— , and Coauthors, 2004b: Atmospheric Emitted Radiance Interferometer. Part II: Instrument performance. J. Atmos. Oceanic Technol., 21, 1777-1789.

Lamb, D., and J. Verlinde, 2011: Physics and Chemistry of Clouds. Cambridge University Press, 417-432.

Li, B., and A. B. Myers, 1990: Absolute Raman cross sections for cyclohexane, acetonitrile, and water in the far-ultraviolet region. J. Phys. Chem., 94, 4051-4054.

Lighthart, B., and A. Mohr, Eds., 1994: Atmospheric Microbial Aerosols. Chapman \& Hall, 397 pp.

Manninen, A., and Coauthors, 2009: Fluorescence cross sections of bioaerosols and suspended biological agents. Appl. Opt., 48, 4320-4328.

Melfi, S. H., K. D. Evans, J. Li, D. Whiteman, R. Ferrare, and G. Schwemmer, 1997: Observation of Raman scattering by cloud droplets in the atmosphere. Appl. Opt., 36, 3551-3559.

Miloshevich, L. M., H. Vömel, D. N. Whiteman, B. M. Lesht, F. J. Schmidlin, and F. Russo, 2006: Absolute accuracy of water vapor measurements from six operational radiosonde types launched during AWEX-G and implications for AIRS validation. J. Geophys. Res., 111, D09S10, doi:10.1029/2005JD006083.
Moran, K. P., B. E. Martner, M. J. Post, R. A. Kropfli, D. C. Welsh, and K. B. Widener, 1998: An unattended cloud-profiling radar for use in climate research. Bull. Amer. Meteor. Soc., 79, 443-455.

Mordy, W., 1959: Computations of the growth by condensation of a population of cloud droplets. Tellus, 11B, 16-44.

Newsom, R. K., 2009: Raman lidar handbook. U.S. Department of Energy Tech. Rep. DOE/SC-ARM/TR-038, 25 pp. [Available online at http://www.arm.gov/publications/tech_ reports/handbooks/rl_handbook.pdf?id=96.]

_ D. D. Turner, B. Mielke, M. Clayton, R. Ferrare, and C. Sivaraman, 2009: The use of simultaneous analog and photon counting detection for Raman lidar. Appl. Opt., 48, 3903-3914.

Pan, Y.-L., and Coauthors, 2007: Bio-aerosol fluorescence. $O p$ tics of Biological Particles, A. Hoekstra, V. Maltsev, and G. Videen, Eds., Springer, 63-104.

Penny, C. M., and M. Lapp, 1976: Raman-scattering cross sections for water vapor. J. Opt. Soc. Amer., 66, 422-425.

Pinnick, R. G., E. Fernandez, J. M. Rosen, S. C. Hill, Y. Wang, and Y. L. Pan, 2013: Fluorescence spectra and elastic scattering characteristics of atmospheric aerosol in Las Cruces, New Mexico, USA: Variability of concentrations and possible constituents and sources of particles in various spectral clusters. Atmos. Environ., 65, 195-204.

Pruppacher, H. R., and J. D. Klett, 1997: Microphysics of Clouds and Precipitation. 2nd ed. Kluwer Academic Publishers, $954 \mathrm{pp}$.

Rizi, V., M. Iarlori, G. Rocci, and G. Visconti, 2004: Raman lidar observations of cloud liquid water. Appl. Opt., 43, 6440-6453.

Russo, F., 2007: An investigation of Raman lidar aerosol measurements and their application to the study of the aerosol indirect effect. Ph.D. dissertation, University of Maryland, Baltimore County, 209 pp.

Sakai, T., T. Nagai, M. Nakazato, Y. Mano, and T. Matsumura, 2003: Ice clouds and Asian dust studied with lidar measurements of particle extinction-to-backscatter ratio, particle depolarization, and water vapor mixing ration over Tsukuba. Appl. Opt., 42, 7103-7116.

Sugimoto, N., Z. Huang, T. Nishizawa, I. Matsui, and B. Tatarov, 2012: Fluorescence from atmospheric aerosols observed with a multi-channel lidar spectrometer. Opt. Express, 20, 20800 20807.

Turner, D. D., 2005: Arctic mixed-phase cloud properties from AERI lidar observations: Algorithm and results from SHEBA. J. Appl. Meteor., 44, 427-444.

_ 2007: Improved ground-based liquid water path retrievals using a combined infrared and microwave approach. J. Geophys. Res., 112, D15204, doi:10.1029/2007JD008530.

_ , and J. E. M. Goldsmith, 1999: Twenty-four-hour Raman lidar water vapor measurements during the Atmospheric Radiation Measurement Program's 1996 and 1997 water vapor intensive observation periods. J. Atmos. Oceanic Technol., 16, 1062-1076. , and —- 2005: The refurbishment and upgrade of the ARM Raman lidar. Proc. 15th Atmospheric Radiation Measurement Science Team Meeting, Daytona Beach, FL, U.S. Department of Energy, 6 pp. [Available online at http://www.arm.gov/ publications/proceedings/conf15/extended_abs/turner_dd1.pdf.] , S. A. Clough, J. C. Liljegren, E. E. Clothiaux, K. Cady-Pereira, and K. L. Gaustad, 2007a: Retrieving liquid water path and precipitable water vapor from Atmospheric Radiation Measurement (ARM) microwave radiometers. IEEE Trans. Geosci. Remote Sens., 45, 3680-3690.

— tance and our challenge. Bull. Amer. Meteor. Soc., 88, 177-190. 
Vaughan, G., D. P. Wareing, L. Thomas, and V. Mitev, 1988 Humidity measurements in the free troposphere. Quart. J. Roy. Meteor. Soc., 114, 1471-1484.

Venable, D. D., D. N. Whiteman, M. N. Calhoun, A. O. Dirisu, R. M. Connell, and E. Landulfo, 2011: Lamp mapping technique for independent determination of the water vapor mixing ratio calibration factor for a Raman lidar system. Appl. Opt., 50, 4622-4632.

Veselovskii, I. A., H. K. Cha, D. H. Kim, S. C. Choi, and J. M. Lee, 2000: Raman lidar for the study of liquid water and water vapor in the troposphere. Appl. Phys., 71B, 113-117.

—, V. Griaznov, A. Kolgotin, and D. N. Whiteman, 2002: Angleand size-dependent characteristics of incoherent Raman and fluorescent scattering by microspheres. 2. Numerical simulation. Appl. Opt., 41, 5783-5791.

Walrafen, G. E., 1967: Raman spectral studies of the effects of temperature on water structure. J. Chem. Phys., 47, 114-126.
Whiteman, D. N., 2003: Examination of the traditional Raman lidar technique. II. Evaluating the ratios for water vapor and aerosols. Appl. Opt., 42, 2593-2608.

— dius, and number density measurements using a Raman lidar. J. Geophys. Res., 104 (D24), 31411-31 419.

, G. E. Walrafen, W.-H. Yang, and S. H. Melfi, 1999: Measurement of an isosbestic point in the Raman spectrum of liquid water using a backscattering geometry. Appl. Opt., 38, 2614-2615.

_ , and Coauthors, 2010: Airborne and ground-based measurements using a high-performance Raman lidar. J. Atmos. Oceanic Technol., 27, 1781-1801.

Zhao, C., and Coauthors, 2012: Toward understanding of differences in current cloud retrievals of ARM ground-based measurements. J. Geophys. Res., 117, D10206, doi:10.1029/ 2011JD016792. 